\title{
Prdm16 and Notch functionally and physically interact during artery development
}

\section{Short title: Prdm16 \& Notch co-regulate aortogenesis}

Manu Beerens ${ }^{1,2}, \mathrm{PhD}$, Jore Van Wauwe ${ }^{1 \dagger}$, Sander $\mathrm{Craps}^{1 \dagger}, \mathrm{PhD}$, Margo Daems ${ }^{1}$, Ashmita $\mathrm{KC}^{2}$,

Chris Finck ${ }^{2}$, Shane Wright ${ }^{2,3}$, Nicholas D. Leigh ${ }^{4}, \mathrm{PhD}$, Calum A. MacRae ${ }^{2 *}, \mathrm{MD}, \mathrm{PhD}$ and Aernout Luttun ${ }^{1 *}, \mathrm{PhD}$

${ }^{1}$ Center for Molecular and Vascular Biology, Department of Cardiovascular Sciences, KU Leuven, Leuven, Belgium; ${ }^{2}$ Department of Medicine, Brigham and Women's Hospital, Harvard Medical School, Boston, MA, USA; ${ }^{3}$ Department of Biomedical Engineering, Boston University, Boston, MA, USA; ${ }^{4}$ Molecular Medicine and Gene Therapy, Wallenberg Centre for Molecular Medicine, Lund Stem Cell Center, Lund University, Sweden.

†These authors contributed equally

*Editorial Correspondence: Aernout Luttun, Department of Cardiovascular Sciences, Center for Molecular and Vascular Biology, Endothelial Cell Biology Unit, KU Leuven, Campus Gasthuisberg, Onderwijs\&Navorsing 1, Herestraat 49, box 911, B-3000 Leuven, Belgium, email: aernout.luttun@kuleuven.be. Calum A. MacRae, Cardiovascular Medicine, Brigham and Women's Hospital, Harvard Medical School, 75 Francis Street, 02115 Boston, MA, USA, email: cmacrae@,bwh.harvard.edu.

SuBJECT TERMS: Developmental Biology; Aortic Coarctation; Cardiovascular Disease; Arteriovenous Malformation; Gene expression/Regulation 


\begin{abstract}
Proper vascular function requires correct arteriovenous (AV) endothelial cell (EC) differentiation. While Notch and its effector Hey2 favor arterial specification, transcription factor (TF) Coup-TFII inhibits Notch activity to induce venous identity. TFs competing with Coup-TFII to orchestrate arterial specification upstream of Notch remain largely unknown. Transcriptional profiling of human and mouse ECs and whole mount in situ hybridization in zebrafish embryos revealed that the TF Prdm16 is exclusively expressed by arterial ECs throughout development, independent of species and hemodynamic factors. Accordingly, prdm16 deficiency in zebrafish perturbed AV specification and caused aberrant shunts between the arterial and venous circulation in an ECautonomous manner. Prdm16 regulated arterial Notch activity both in vitro and in vivo and simultaneous knockdown of notch aggravated the vascular defects observed in prdm16 morphant zebrafish. In vitro studies revealed that Prdm16 did not alter the levels of the transcriptionally active, intracellular domain of the Notch1 receptor (N1ICD). Rather, it boosted Notch signaling by physically and functionally interacting with both N1ICD and the Notch downstream effector Hey2. Together, these data demonstrate the hitherto unexplored role for Prdm16 during arterial development, by its dual activity on arterial canonical Notch during embryogenesis.
\end{abstract}

Keywords: Prdm16, arterial endothelial specification, artery formation, canonical Notch signaling, arterial disease

\title{
$\underline{\text { Non-standard Abbreviations and Acronyms }}$
}
AV
arteriovenous

bHLH basic helix-loop-helix

BOECs blood outgrowth endothelial cells

coA co-activator 


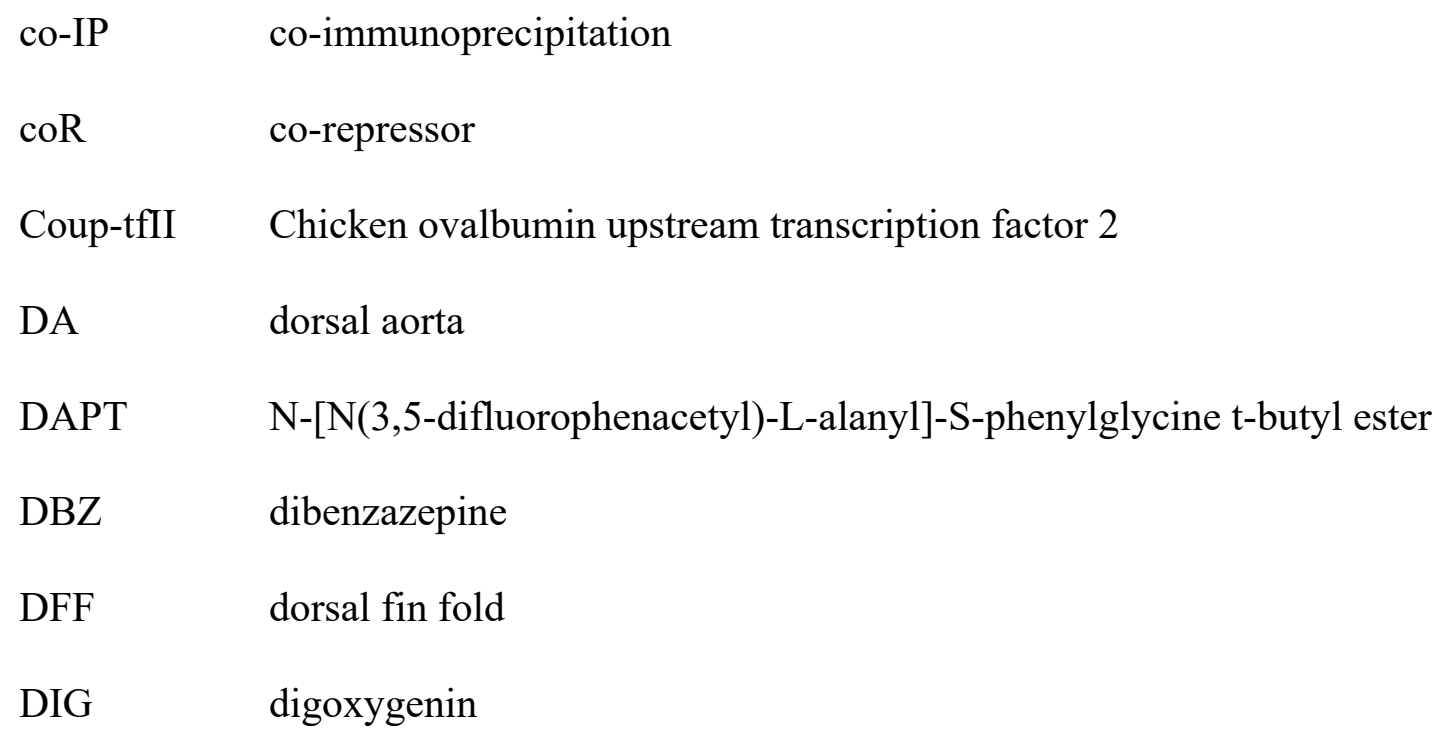

GSEA Gene Set Enrichment Analysis 


\begin{tabular}{|c|c|}
\hline GWAS & Genome-Wide Association Studies \\
\hline HEK & human embryonic kidney \\
\hline Hey & Hes-Related Family bHLH Transcription Factor with YRPW Motif \\
\hline hpf & hours post-fertilization \\
\hline HUAECs & human umbilical artery endothelial cells \\
\hline HUVECs & human umbilical vein endothelial cells \\
\hline $\mathrm{IHC}$ & immunohistochemistry \\
\hline ISV & intersomitic vessel \\
\hline $\mathrm{KO}$ & knockout \\
\hline Mo & morpholino \\
\hline NICD & Notch receptor intracellular domain \\
\hline NFR & nuclear fast red \\
\hline $\mathrm{PCV}$ & posterior cardinal vein \\
\hline Prdm & Positive regulatory domain-containing protein \\
\hline qRT-PCR & quantitative real-time PCR \\
\hline $\mathrm{r}$ & recombinant \\
\hline RBPJ- $\kappa$ & Recombination Signal Binding Protein for Immunoglobulin Kappa J \\
\hline SEM & standard error of the mean \\
\hline Sox & SRY-Box Transcription Factor \\
\hline $\mathrm{TF}$ & transcription factor \\
\hline ISH & situ hybridization \\
\hline
\end{tabular}




\section{INTRODUCTION}

Finely tuned specification of endothelial cells (ECs) into arterial and venous lineages is essential for proper vascular development and function. While Notch is a prerequisite for arterial endothelial specification in zebrafish, ${ }^{1-6}$ mice $^{7-9}$ and human cells, ${ }^{10,11}$ the transcription factor (TF) chicken ovalbumin upstream transcription factor 2 (COUP-TFII) inhibits canonical Notch signaling and instructs ECs to adopt a venous identity. ${ }^{12-14}$ Concordantly, aberrant Notch activity results in severe vascular defects, including the occurrence of arteriovenous (AV) malformations or shunts that can be life-threatening. ${ }^{15-17}$ Despite its clinical relevance, our understanding of the molecular events and transcriptional machinery governing arterial endothelial specification upstream of or parallel to canonical Notch activity remains incomplete. A better comprehension of these mechanisms will result in more profound knowledge on vascular development and disease and may lead to novel insights into overarching principles of Notch-mediated lineage specification outside the cardiovascular system.

Positive regulatory domain-containing (Prdm)16 belongs to a TF family involved in binary cell fate decisions. In adipose tissue, Prdm16 is exclusively expressed by and regulates the transcriptional program of brown/beige adipocytes, while concomitantly suppressing white adipose-specific gene expression. ${ }^{18,19}$ In contrast, COUP-TFII drives white adipogenesis and Coup-TFII ${ }^{+/-}$mice have a marked upregulation of brown adipose-selective genes in white fat deposits, including $\operatorname{Prdm} 16 .{ }^{20}$ This mutual expression pattern is also evident within the cardiovascular system, where Prdm16 and Coup-TFII are exclusively expressed by ventricular and atrial cardiomyocytes, respectively, in line with their corresponding roles in ventricular and atrial physiology. Although we $\mathrm{e}^{21}$ and others ${ }^{22}$ previously reported the arterial-specific expression pattern of Prdm16 in the adult vasculature, it remains unknown if Prdm16 is exclusively expressed by 
arterial ECs during development and whether Prdm16 and Coup-TFII also act as opposing forces in fate decisions made by vascular (precursor) cells.

Intriguingly, while Coup-TFII inhibits the expression of the Notch downstream effector HEY2 (Hes-Related Family bHLH Transcription Factor with YRPW Motif 2) in ECs, we previously demonstrated that $\sim 70 \%$ of genes regulated by HEY2 in human umbilical vein ECs (HUVECs) were equally controlled by Prdm $16 .{ }^{21}$ Furthermore, others have reported the intricate interplay between Prdm family members and Notch ${ }^{23-25}$ and the direct binding of Prdm proteins to basic helix-loop-helix (bHLH) TFs - a TF family to which HEY2 belongs - in various cell types. ${ }^{26,27}$ Together, these data indicate that Prdm16 may play a key role during arterial specification through, in contrast to Coup-TFII, positive modulation of Notch or Hey2 activity.

Here, we investigated whether Prdm16 also orchestrates arteriovenous endothelial specification, arterial morphology and arterial Notch activity during development. Our results illustrate that Prdm16 is present in arterial ECs at the earliest developmental stages in zebrafish and mammals. Furthermore, by using a combination of genetic and pharmacological approaches in zebrafish embryos and primary human EC (progenitor)s, we demonstrate that endothelial Prdm16 is indispensable for arterial endothelial differentiation and vascular development, by activating and potentiating the canonical Notch pathway. Finally, we provide evidence for a direct protein-protein interaction between Prdm16 and both the Notch1 receptor intracellular domain (N1ICD) and HEY2, highlighting the complex interaction between Prdm16 and canonical Notch signaling in arterial ECs. 


\section{METHODS}

Extended methods and a Major Resources Table (Online TableI) are provided online.

\section{Data availability}

The majority of supporting data are presented within this article and online. Data not directly presented are available from the corresponding author upon request. Microarray data will be made accessible at the Gene Expression Omnibus website.

\section{EC isolation, profiling and drug treatment}

Human ECs were isolated from umbilical cords (HUVECs) and peripheral blood (blood outgrowth ECs or BOECs) as described online. To study Prdm16 overexpression effects, BOECs were transduced with pRRL2-empty-PGK-Cherry or pRRL2-Prdm16-PGK-Cherry lentiviral particles and RNA was collected 6 days later. RNA from 3 experiments was used for microarray (Affymetrix HG-U133 Plus2.0 GeneChip). Data processing and functional annotation analyses were performed as described online. Inhibition or activation of Notch signaling was established by adding $\mathrm{N}$-[N(3,5-difluorophenacetyl)-L-alanyl]-S-phenylglycine t-butyl ester (DAPT) or by culture on recombinant delta-like ligand 4 (rDLL4)-containing gelatin, respectively. The use of human cells was approved by the Ethics Committee of University Hospitals Leuven. Mouse ECs were isolated by fluorescence-activated cell sorting (FACS) from the thoracic aorta and vena cava from Tie2-GFP mice. ${ }^{28}$ RNA from 5 selected isolations per tissue was used for microarray (Affymetrics Mo Gene1.0 ST array) and a species-conserved AV signature was defined by conducting a meta-analysis on this and our previous human AV signature, ${ }^{21}$ as described online. Mouse studies were approved by the Ethical Committee of the animal facilities at KU Leuven. Zebrafish ECs were isolated by FACS from $T g(k d r: e G F P)^{s 843}$ embryos. $^{28}$ 


\section{Lentiviral production and transduction}

Lentiviral particles were produced in human embryonic kidney (HEK)293 cells after cotransfection with helper plasmids (psPax2 and PMD2G) and pRRL2-empty-PGK-Cherry or pRRL2-mPrdm16-PGK-Cherry. For transduction, cells were plated in 24-wells 24 hours prior to lentivirus exposure and RNA lysates were collected 6 days later using TRIzol® (Invitrogen). For Western blotting, cells were collected in Laemmli buffer supplemented with proteinase/phosphatase inhibitors.

\section{Luciferase Assays}

Cells were transduced with pRRL2-mPrdm16-PGK-Cherry lentiviral particles, combined with a Recombination Signal Binding Protein for Immunoglobulin Kappa J (RBPJк)-luciferase reporter virus and a lentiviral Renilla control to normalize for transduction efficiency. Six days later, cells were collected in lysis buffer and Firefly/Renilla luciferase activity were measured according to the manufacturers' protocol using the Dual-Luciferase ${ }^{\circledR}$ Reporter Assay System (E1910; Promega) on a Microplate Luminometer LB 96V (EG\&G Berthold). To measure HEY1 and HEY2 promoter activity, cells were co-transfected with pRRL2-mPrdm16-PGK-Cherry (or pRRL2empty-PGK-Cherry control), pTK-renilla and pGL3-HEY1:luc or pGL3-HEY2:luc (kind gifts from Dr. Manfred Gessler) and Firefly/Renilla luciferase activity was measured 24 hours later.

\section{Expression analysis}

Embryonic day (E)9.5 or E10.5 embryos of Prdm 16 $6^{\text {Gt683Lex }}$ mice ${ }^{29}$ (Mouse Mutant Resource Repository Center) were stained whole mount for $\beta$-galactosidase activity, as described online.

For Prdm16 immunohistochemistry (IHC) staining, E14.5 or E17.5 FvB mouse embryos were dissected and snap-frozen in liquid nitrogen. Unfixed cryopreserved embryos were sectioned and stained with sheep-anti-Prdm16 antibody (AF6295, R\&D Systems) and FITC-conjugated anti- 
aSMA (F3777, Sigma). A similar procedure was followed to stain human umbilical cords for PRDM16. For whole mount in situ hybridization (WISH), AB/TU zebrafish embryos were collected and fixed with 4\% PFA. Digoxygenin (DIG)-labeled probes were used and probe binding was revealed with anti-DIG-AP antibody followed by chromogenic detection based on alkaline phosphatase activity, as described online. Whole mount pictures were taken using a Zeiss Axio Imager Z1 microscope. Alternatively, embryos were paraffin-embedded, sectioned and counterstained with nuclear fast red (NFR).

\section{RNA/cDNA preparation, qRT-PCR, co-immunoprecipitation (co-IP) and Western blotting}

Total RNA was extracted from cultured ECs, cDNA was prepared using the Superscript III First Strand Kit and for qRT-PCR, SYBR green dye was used during amplification on a Step One Plus (Applied Biosystems). A primer list is added in Online TableII. For co-IP, HEK293 cells were plated and transfected with different combinations of pRRL2-Myc-Prdm16-PGK-Cherry; pRRL2Myc-empty-PGK-Cherry; $\quad$ pReceiverM04-GST-HEY2, $\quad$ pReceiverM04-GST-N1ICD, pReceiverM04-GST-CTBP2 and pReceiverM04-GST-GFP plasmids (GeneCopoeia) 24 hours later. IP lysates were incubated with anti-Myc antibody-conjugated dynabeads, as described online and bound proteins were isolated by boiling the dynabeads once resuspended in Laemmli buffer and magnetic removal of the dynabeads. Western blotting was performed as described online, pictures were recorded with a Chemidoc XRS+ imager (Bio-Rad laboratories) and band density analysis was performed using NIH Image software.

\section{In vivo zebrafish experiments}

Zebrafish husbandry and procedures were approved by the Harvard Medical Area Standing Committee on Animals, the local Institutional Animal Care and Use Committee. Zebrafish embryos were incubated at $28.5^{\circ} \mathrm{C}$ in standard E3 medium. Confocal images were taken on a 
Fluoview FV1000 (Olympus) to visualize the vasculature or analyzed with ImageJ software to assess canonical Notch activity in the dorsal aorta (DA) or whole embryo where indicated. Cardiac performance was measured as previously described. ${ }^{30}$ Angiograms were generated by video microscopy of laterally positioned embryos using an Axioplan (Zeiss) upright microscope equipped with a FastCam PCI high-speed digital camera (Photron) and subsequent digital image subtraction in ImageJ. For morpholino (Mo)-mediated knockdown, antisense Mo oligomers (GeneTools LLC) targeting prdm16, dll4, rbpj, hey2 (Online TableII) were injected at the onecell stage. For acute CRISPR-mediated knockout (KO), four guide RNA's targeting exon 9 of zebrafish prdm16 were designed using CHOPCHOP (https://chopchop.cbu.uib.no/). cRNA's were synthesized (Integrated DNS Technology), annealed with tracrRNA and mixed with Alt-R Cas9 protein to form the ribonucleoprotein complex. Two $\mathrm{nl}$ of this complex was injected into the cell of one-cell stage zebrafish embryos. Cas9 protein was omitted from the complex as a control. Embryos were exposed to DAPT $(25 \mu \mathrm{M})$, dibenzazepine (DBZ; $250 \mathrm{nM})$ or vehicle (dimethyl sulfoxide; DMSO) from 6 hours post-fertilization (hpf) onwards until imaging.

\section{Statistical Analyses}

Quantitative data are presented as mean \pm standard error of the mean (SEM). Detailed information on statistical analysis is provided online. 


\section{RESULTS}

\section{Prdm16's expression is compatible with a role in AV specification during development}

To identify novel determinants of arterial specification and morphology, we performed whole genome transcriptional profiling of freshly isolated arterial and venous ECs of mouse origin, in analogy to our previously established human dataset. ${ }^{21}$ To further characterize the exact gene signature that defines arterial or venous identity of ECs across species, we conducted a

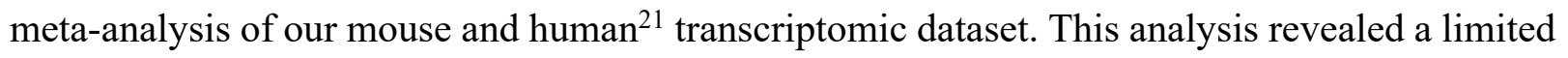
set of 52 genes - including Hey2 and Coup-TFII, with an arterial-specific or venous-restricted expression pattern conserved across species (Online Fig.Ia; Online TableIII). Notably, many other of these genes had previously documented arterial or venous-specific endothelial expression patterns and had been implicated in arteriovenous specification of ECs, strongly implicating that our approach could lead to the identification of novel determinants of arterial EC differentiation (Online TableIII). Accordingly, gene ontology (GO) analysis revealed enrichment for key biological processes like 'circulatory and cardiovascular system development', 'aorta development', 'blood vessel morphogenesis' and 'artery development' (Online TableIV).

Intriguingly, Prdm16 was - together with Hey2 - one of only 3 arterial-specific TFs emerging from our meta-analysis, indicating that Prdm16 was part of the larger gene signature that defined arterial or venous identity of ECs across species, in agreement with our previous findings in human ECs. ${ }^{21}$ Using Hey2 and Coup-TFII as markers of arterial and venous endothelial identity respectively, we verified that Prdm16 was highly enriched in arterial ECs from human umbilical cords (Online Fig.Ib) and mouse thoracic aorta (Online Fig.Ic). $\beta$ galactosidase activity staining on embryonic day (E)9.5 and E10.5 embryos of the Prdm16 ${ }^{\text {Gt } 683 \text { Lex }}$ 
reporter mouse strain revealed that arterial-specific Prdm16 expression was established early during development in the intra- and extraembryonic vasculature (Fig.1a-f) and maintained throughout development and across different AV pairs as evidenced by immunohistochemistry stainings in E14.5 and E17.5 embryos (Fig.1g-l'). Accordingly, we detected PRDM16 protein in ECs lining the human umbilical artery but not umbilical vein (Fig.1m,n). Consistent with these findings, Genotype-Tissue Expression (GTex) database analysis revealed high PRDM16 mRNA levels in aortic, coronary and tibial artery tissues (Online Fig.Id).

We then analyzed whether prdm16 was also enriched in arterial ECs of developing zebrafish. Expression analysis of sorted eGFP+ECs from $\operatorname{Tg}(k d r l: e G F P)^{s 843} z^{2}$ brafish embryos ${ }^{28}$ throughout development demonstrated endothelial enrichment of prdm 16 at $24 \mathrm{hpf}$, consistent with its potential role during AV endothelial specification (Online Fig.Ie). WISH revealed that prdm16 is exclusively expressed by ECs of the DA, but not the posterior cardinal vein (PCV) prior to the onset of flow and as early as $18 \mathrm{hpf}$ (Fig.10). As in mice, arterial prdm 16 expression persisted throughout development as evidenced by WISH at 20, 22, 24 and 30 hpf (Fig.1p; Online Fig.II) and confocal imaging of the $t u d 28 G t$ prdm16 reporter $\operatorname{line}^{31}$ at $48 \mathrm{hpf}$ and 6 days post-fertilization (dpf; Fig.1q-r').

\section{Prdm16 controls arterial development in an EC-autonomous manner}

Interestingly, Mo-mediated prdm16 knockdown studies in $\operatorname{Tg}(k d r l: e G F P)^{s 843}$ zebrafish embryos revealed dose-dependent vascular defects, hallmarked by abnormal arterial intersomitic vessel (ISV) development, consistent with a previous report, ${ }^{32}$ and aortic hypoplasia at 24 hpf (Fig.2a-d). These vascular malformations persisted throughout development as $48 \mathrm{hpf}$ prdm16 morphants frequently displayed impaired ISV growth, reduced aortic diameters (Fig.2e-h') and, occasionally, aortic coarctation and/or AV shunting between axial vessels, while controls did not 
(Fig.2h,h'; Online MoviesI,II). These phenotypes were independent of p53 activation, as concomitant knockdown of prdm16 and $p 53$ resulted in similar phenotypes and were replicated by a splice-site Mo ('Mo2') (data not shown).

Of note, the severe cardiac defects in prdm 16 morphants, in line with Prdm16's described role during cardiac development, ${ }^{30,33}$ precluded the visualization and reliable quantification of aortic anomalies due to the absence of flow. To assess the vascular effect of prdm 16-deficiency independent of hemodynamics, we generated $\operatorname{Tg}(\mathrm{cmlc} 2: P R D M 16)$ zebrafish which overexpress human full-length PRDM16 in their cardiomyocytes. As expected, $\operatorname{Tg}(\mathrm{cmlc} 2: P R D M 16)$ zebrafish were partially protected from prdm16 Mo-induced cardiac defects and more often carried flow through their vessels compared to control $\operatorname{Tg}(\mathrm{cmlc} 2: G F P)$ embryos. Importantly, AV shunts were more frequently observed in prdm16 Mo-injected $\operatorname{Tg}(\mathrm{cmlc2}$ :PRDM16) compared to $\operatorname{Tg}(\mathrm{cmlc2}: G F P)$ embryos (33\% vs. 5\%; Fig.2i,j; Online MoviesIII,IV), suggesting that noncardiomyocyte cell-types mediate the vascular defects observed in prdm16 morphants.

We next created $\operatorname{Tg}(f l i l a: m P r d m 16 ; \operatorname{Tg}(k d r l: d s R e d))$ zebrafish overexpressing mouse (m)Prdm16 in dsRed ${ }^{+}$ECs. Although Tg(flila:mPrdm16;kdrl:dsRed) larvae did not display vascular defects under baseline conditions compared to $T g(k d r l: d s R e d)$ controls (Fig.2k,l) ectopic mPrdm16 in ECs protected against prdm16 Mo-induced DA hypoplasia (Fig.2m-n'; Online MovieV). Angiographies further revealed that $\operatorname{Tg}(f l i l a: m P r d m 16 ; k d r l: d s R e d)$ larvae less frequently displayed AV shunts upon prdm16 Mo knockdown (Fig.20-r') compared to control embryos (20\% vs. >40\%; Fig.2s), highlighting the EC-autonomous role of prdm16 during arterial development. 


\section{Prdm16 activates Notch signaling and regulates $A V$ endothelial expression in vitro}

To unravel the molecular mechanisms behind our in vivo phenotypes, we performed whole genome transcriptomics on human endothelial progenitor cells (BOECs) overexpressing mPrdm16 or Cherry as a control. GO analysis revealed that Prdm16 influenced genes involved in aorta/artery development and morphogenesis, in line with the arterial defects observed in prdm16-deficient zebrafish embryos (Online TableV). Notably, gene set enrichment analysis (GSEA) indicated that Prdm16 regulated pathways instrumental for arterial endothelial specification and artery development, including the Notch and HES-HEY signaling cascade (Fig.3a). More detailed analysis emphasized that the inductive effect of Prdm16 on the Notch pathway was most profound on Notch components with a reported arterial-restricted expression profile (Fig.3b; red bars). Accordingly, mRNA levels of the Notch pathway members DLL4, HEY1, HEY2 and EphrinB2 (EFNB2) were significantly increased in HUVECs overexpressing mPrdm16 compared to control cells, while expression of the venous-restricted marker Neuropilin-2 (NRP2) was downregulated

(Fig.3c). The enhanced expression of $H E Y 1 / 2$ corresponded with increased promoter activity (Online Fig.IIIa,b) and with considerably higher levels of canonical Notch activity in both HUVECs and BOECs (Fig.3d,e). This effect was dependent on the presence of NICD, as Prdm16 failed to induced Notch in the presence of the $\gamma$-secretase inhibitor DAPT in both HUVECs and BOECs (Fig.3f,g; Online Fig.IIIc). Importantly, Prdm16 also induced the expression of previously published (e.g., Gap junction protein alpha 5; GJA5)) ${ }^{34,35}$ and de novo identified (e.g., Dickkopf WNT signaling pathway inhibitor 2; DKK2) arterial-specific markers in a canonical Notch-dependent manner in both HUVECs and BOECs (Online Fig.IIId,e). Conversely, Prdm16 failed to suppress NRP2 mRNA levels in the presence of DAPT (Online Fig.IIId) indicating that 
Prdm16 defines a broader arterial endothelial program through modulating canonical Notch activity.

\section{Prdm16 drives Notch signaling to orchestrate arteriovenous EC identity in vivo}

Dose-dependent knockdown of prdm16 in the canonical Notch reporter line $\operatorname{Tg}(T p 1: e G F P)^{u m 14},{ }^{36}$ demonstrated that prdm16 also determines Notch signaling in vivo (Fig.4ad), as evidenced by the loss of eGFP signal in the DA (Fig.4a'-d',e). Loss of arterial Notch activity was accompanied by ectopic expression of venous markers flt4, dab2 and $n r p 2 a$ in the DA of 30 hpf prdm 16 morphants (Fig.4f-k) and the occurrence of AV shunts between the axial vessels of prdm16 morphant, but not control embryos at 48 hpf(Fig.4l; Fig.2o,q).

In vivo, Prdm16 alone was not sufficient to induce Notch signaling within the venous vasculature as $\operatorname{Tg}(f l i 1 a: m P r d m 16) ; \operatorname{Tg}(\operatorname{Tp} 1: e G F P)^{u m 14}$ double transgenic zebrafish did not display ectopic Notch activity in the PCV. However, while prdm16 knockdown severely reduced canonical Notch activity in the DA of $\operatorname{Tg}(T p 1: e G F P)^{u m 14}$ embryos, this effect was largely attenuated in the DA of $\operatorname{Tg}(f l i 1 a: m P r d m 16) ; \operatorname{Tg}(T p 1: e G F P)^{u m 14}$ embryos (Fig.4m-p). Importantly, excess mPrdm16 did not rescue the profound loss of canonical Notch activity in the whole embryo, demonstrating endothelial-specific retention of canonical Notch in Tg(flila:mPrdm16); $\operatorname{Tg}(T p 1: e G F P)^{u m 14}$ embryos (Fig.4q). We next tested whether endothelialspecific overexpression of mPrdm16 would protect against DAPT-induced loss of arterial Notch activity. Similarly to our results with prdm16 knockdown, we observed that the repressive effect of DAPT on arterial Notch activity was attenuated in $\operatorname{Tg}(f l i 1 a: m P r d m 16) ; \operatorname{Tg}(\operatorname{Tp} 1: e G F P)^{u m 14}$ compared to $\operatorname{Tg}(T p 1: e G F P)^{u m 14}$ embryos (Fig.4r-v; Fig.4r"-u"), despite the near absence of canonical Notch activity in non-vascular tissues in both $\operatorname{Tg}(f l i 1 a: m P r d m 16) ; \operatorname{Tg}(\operatorname{Tp} 1: e G F P)^{\text {um14 }}$ 
and $\operatorname{Tg}(T p 1: e G F P)^{u m 14}$ embryos. Together, these data support an EC-autonomous role for prdm16 during AV cell-fate specification and arterial development.

\section{Prdm16 and Notch interact in ECs during early vascular development}

As the vascular defects in prdm16 morphants closely resemble those observed in Notch deficient zebrafish, ${ }^{1,2,4,6}$ we examined the in vivo interaction between prdm16 and Notch in more detail. We therefore injected $\operatorname{Tg}(k d r l: e G F P)^{s 843}$ embryos with a subthreshold dose of the prdm16 Mo and partially blocked distinct members of the canonical Notch signaling cascade. The latter starts with binding of Notch ligand DLL4 to its cognate receptors Notch1/4 and results in active transcription of the Notch downstream effectors Heyl and Hey2 (Fig.5a). As expected, partial loss of prdm16 did not perturb vascular morphology nor did it result in AV shunts when Notch signaling is not perturbed (Fig.5a-d).

Knockdown of the main endothelial Notch ligand, dll4, in zebrafish does not result in vascular defects (Fig.5e). We therefore tested if partial loss of prdm16 would induce arterial abnormalities in dll4-deficient zebrafish embryos. In agreement with previous findings, we did not observe overt vascular defects in dll4 morphant embryos. However, more than $40 \%$ of compound prdm16/dll4 morphants displayed aortic coarctation of the DA or AV shunts (Fig.5f-i; Online MoviesVI-IX).

The vascular deficits of Dll4 ${ }^{-/-}$mice ${ }^{37-39}$ are mirrored in mice lacking one allele of both Notch 1 and Notch $4 .{ }^{9}$ We therefore treated control or $p r d m 16$ morphant $T g(k d r l: e G F P)^{s 843}$ embryos with $\gamma$-secretase inhibitor DAPT - which prevents cleavage of all Notch receptors (Fig.5j). DAPT treatment did not affect vascular development in control embryos but robustly induced aortic coarctation and AV shunts in $\sim 50 \%$ of embryos injected with a suboptimal dose of prdm $16 \mathrm{Mo}$, 
reminiscent of the phenotypes observed in prdm16/dll4 double morphants (Fig.5k-n; Online MoviesX,XI). Similar results were obtained with a second prdm16 Mo ('Mo2') (Online Fig.IVaf), or in the presence of another $\gamma$-secretase inhibitor (DBZ; Online Fig.IVg-I). In line with these findings, we detected residual canonical Notch activity in the DA of $\operatorname{Tg}(\operatorname{Tp} 1: e G F P)^{u m 14}$ embryos after partial knockdown of prdm16 or DAPT treatment, while prdm16 morphants dosed with DAPT were completely devoid of arterial Notch activity at 24 and 48 hpf (Online Fig.IVm-t'). Similar results were observed with DBZ (not shown). To validate our Mo-based results, we adopted an acute CRISPR KO system shown to generate complete null phenotypes in F0 zebrafish. ${ }^{40}$ Acute $\mathrm{KO}$ of prdm16 did not result in overt vascular phenotypes but was associated with DAPT-induced vascular malformations at 48 hpf (Online Fig.Va-e) reminiscent of those observed in our Mo studies. Hence, both antisense Mo- and CRISPR-mediated knockdown/KO of prdm16 sensitize to arteriovenous shunt formation when canonical Notch is inhibited.

In the absence of RBPJк, ECs fail to undergo correct arterial differentiation and Heyl/2 promoter activity remains low (Fig.5o), coinciding with the occurrence of AV shunts both in zebrafish embryos ${ }^{1}$ and in adult mice. ${ }^{41}$ AV shunts were not observed upon partial knockdown of rbpj using a previously validated $r b p j a / b$ Mo $\left(\right.$ ref. $^{42}$ ) in zebrafish embryos (Fig.5p,s; Online MovieXII), but partial knockdown of both prdm16 and rbpj phenocopied the vascular deformations observed in prdm16/dll4 double-morphants and prdm16 morphants treated with $\gamma$ secretase inhibitors (Fig.5q-s). Occasionally, prdm16/rbpj morphants exhibited partial loss of the DA, with blood flow bypassing the missing arterial segment through sequential ISVs ('aortic skipping'; Fig.5r,s; Online MovieXIII). 
Endothelial overexpression of the dominant-negative PRDM16 ${ }^{K 702 Q}$ variant sensitizes to DAPTinduced AV shunting

To specifically analyze the interaction between Prdm16 and Notch within the endothelium, we leveraged the dominant-negative effect of the pathogenic PRDM16 ${ }^{\mathrm{K} 702 \mathrm{Q}}$ variant $^{30}$ and created zebrafish overexpressing PRDM16 $6^{\mathrm{K} 702 \mathrm{Q}}$ in ECs using the UAS-Gal4 driver system. Tg(kdrl:Gal4;UAS:PRDM16 ${ }^{K 702 Q}$ ) double transgenic (DT) embryos did not display overt vascular anomalies under baseline conditions (Fig.6a,b; Online MovieXIV), most likely due to the presence of endogenous zebrafish prdm16. Likewise, we did not observe significant vascular defects in $\operatorname{Tg}(k d r l: G a l 4)$ or $\operatorname{Tg}\left(U A S: P R D M 16^{K 702 Q}\right)$ control embryos treated with DAPT. Strikingly however, $>50 \%$ of $\operatorname{Tg}\left(\mathrm{kdrl}: \mathrm{Gal4} ; U A S: P R D M 16^{K 702 Q}\right)$ embryos displayed AV shunts when treated with DAPT (Fig.6c-e; Online MovieXV). Notably, cardiac performance (heart rate, stroke volume and cardiac output) did not differ between $\operatorname{Tg}\left(k d r l: G a l 4 ; U A S: P R D M 16^{K 702 Q}\right)$ and control embryos in the presence or absence of DAPT (Fig.6f-h). Thus, EC-specific overexpression of PRDM16 ${ }^{\mathrm{K} 702 \mathrm{Q}}$ exerts a dominant-negative effect in ECs and predisposes zebrafish embryos to AV shunting induced by canonical Notch inhibition.

\section{Prdm16 amplifies the endothelial response downstream of a given NICD input signal}

In vitro, excess Prdm16 was able to amplify the endothelial response to recombinant (r)Dl14, the main Notch ligand in arterial ECs: while both ectopic mPrdm16 and rD114 treatment increased DLL4, HEY1 and HEY2 mRNA levels compared to Cherry- or BSA-treated cells respectively, rDll4-treated mPrdm16 cells displayed much higher levels of core Notch pathway components (Fig.7a). Vice versa, mRNA levels of the venous markers COUP-TFII, NRP2, Endomucin (EMCN) and Fibronectin Leucine Rich Transmembrane Protein 2 (FLRT2) trended downwards in rDll4+mPrdm16 HUVECs (Online Fig.VIa). Concordantly, DLL4 protein levels 
were higher and FLRT2 protein levels lower in rD114+mPrdm16 HUVECs despite similar levels of mPrdm16-overexpression in BSA-mPrdm16 and rDl14+mPrdm16 cells (Online Fig.VIb,c). A similar synergistic effect was observed in BOECs for the classical D114-HEY1/2 cascade and for the arterial-specific markers GJA5 and DKK2 (Online Fig.VId,e). As in HUVECs, rD114+mPrdm16 BOECs displayed lower $N R P 2$ and EPHB4 mRNA levels (Online Fig.VIf) compared to BSA-mPrdm16 or rD114+Cherry BOECs. Surprisingly, Western blot analysis for the cleaved, activated form of the NOTCH1 receptor, revealed similar N1ICD levels in mPrdm16 ('mPrdm16') versus Cherry-overexpressing ('Cherry') HUVECs (Fig.7b), despite elevated mRNA levels for DLL4, HEY1 and HEY2. Co-Immunoprecipitation (Co-IP) experiments including the known Prdm16 binding partner, CtBP2 as positive control, further demonstrated that Prdm16 and N1ICD reside in the same protein complex (Fig.7c). Together with the inability of Prdm16 to induce Notch in the presence of DAPT, these results demonstrate that Prdm16 does not strengthen canonical Notch signaling by increasing NICD levels, but rather through amplification of an NICD input signal, most likely by direct or indirect interaction with NICD at Notch target loci.

\section{Prdm16 orchestrates arterial development by its physical and functional interaction with Hey2}

Additional co-IP studies confirmed that PRDM16 also complexes with HEY2 (Fig.7d), potentially further fine-tuning canonical Notch through this mechanism. Therefore, to test the impact of this physical interaction on arterial development, we partially knocked-down prdm 16 or hey2 alone or in combination in zebrafish larvae. Compound prdm16/hey2 morphants exhibited AV shunts and aortic coarctation defects while virtually all hey2 or prdm16 single morphants developed normally (Fig.7e-f). To further underline the interplay between Prdm16 and Hey2, we utilized the hey2 hypomorph zebrafish mutant, gridlock $\left(g r l^{m 145 / m 145}\right) .{ }^{6}$ We crossed phenotypically normal $\mathrm{grl}^{\mathrm{m} 145 /+}$ fish with $\mathrm{Tg}(\mathrm{kdrl}: e G F P)^{s 843}$ zebrafish and injected these embryos with a low dose 
of the prdm16 Mo. Partial prdm16 knockdown did not evoke vascular defects in wild-type embryos, but triggered aortic coarctation and AV shunting in $T g(k d r l: e G F P)^{s 843} ; g r l^{m 145 /+}$ embryos (Fig.7g,h; Online MoviesXVI,XVII).

Altogether, our data indicate that Prdm16 is exclusively expressed by arterial ECs throughout all developmental stages and independent of species. More importantly, we provide evidence that Prdm16 shapes the vasculature during development by finely coordinating AV endothelial specification. Like in other tissues, the vascular expression pattern of Prdm16 is mutually exclusive to that of Coup-TFII. Mechanistically, our data illustrate that, opposite to Coup-TFII, Prdm16 controls arterial cell fate and artery development by positively impacting canonical Notch signaling, through amplifying NICD activity and, more downstream, by binding to the main arterial Notch effector, Hey2. 


\section{DISCUSSION}

Incorrect arteriovenous endothelial differentiation can lead to developmental defects or cause life-threatening vascular disease at later stages, but the exact molecular mechanisms orchestrating this event remain incompletely understood. This is partly due to the phenotypic drift of ECs upon culture, ${ }^{43-45}$ emphasizing the need to study ECs in their native environment. Here, we obtained transcriptomic profiles of freshly isolated arterial and venous ECs from mice and, in combination with our previous human dataset, ${ }^{21}$ identified a unique list of 52 arterial/venousspecific genes in mammalian ECs to which Prdm16 belonged. $\mathrm{We}^{23}$ and others ${ }^{24,46}$ have previously reported arterial enrichment for Prdm16 in various settings. More recently, we demonstrated that Prdm16 controls vascular maintenance in mice postnatally, ${ }^{47}$ while Matrone and colleagues used zebrafish to demonstrate that Prdm16 positively regulates developmental angiogenesis. ${ }^{32}$ Despite these findings, the functional role of Prdm16 within the developing vasculature remains elusive.

By detailed analysis of Prdm16's expression pattern across species, we provide evidence that Prdm16 co-defines arteriovenous identity of ECs in mammals and zebrafish across the vascular system, irrespective of developmental stage, anatomical location and hemodynamic factors. Studies in zebrafish embryos further revealed that the cardiovascular role of prdm 16 extends beyond the heart muscle, ${ }^{30,33}$ as prdm 16 deficiency resulted in profound arterial defects, in an EC-autonomous manner, as EC-specific overexpression of mPrdm16 rescued the vascular abnormalities observed in prdm16 morphants.

Canonical Notch signaling coordinates arterial endothelial differentiation in zebrafish, ${ }^{1-6}$ mice e $^{7,38,39,41,48}$ and human ECs, ${ }^{10,11,49,50}$ while Coup-TFII is instrumental for establishing a venous identity. ${ }^{12-14}$ Although several other TFs - most notably Sox family members ${ }^{3,51}$ and FoxC1/2 (refs. ${ }^{49,50}$ ) - have been implicated in Notch-mediated AV specification, our knowledge on the 
upstream mechanisms that tightly coordinate Notch is incomplete. We show that Prdm16 regulates canonical Notch activity to coordinate AV specification in ECs, simultaneously suppressing the venous EC program, in analogy with its role in adipogenesis. ${ }^{18,19}$ We further defined an epistatic interaction between prdm16 and canonical Notch in zebrafish embryos, where combined, but partial, inhibition of prdm16 and Notch components invariably resulted in vascular defects resembling those observed in zebrafish ${ }^{1,2,4-6,52}$ or mouse ${ }^{53-57}$ Notch mutants.

A positive link between Prdm proteins and the Notch pathway was previously reported in mice $^{24}$ and zebrafish. ${ }^{25,58}$ However, hamlet - the drosophila Prdm16 homologue - negatively impacts Notch during drosophila neurogenesis, ${ }^{23}$ while in adipose tissue canonical Notch suppresses Prdm16 to drive white adipogenesis. ${ }^{59}$ Altogether, these data indicate that Prdm proteins and the Notch pathway regulate various binary cell fate decisions by modulating each other's activity in a context-dependent manner, the definition of which is unknown.

Acute $\mathrm{KO}$ of prdm16 did not result in obvious vascular defects under baseline conditions, suggesting that other prdm family members might compensate for complete loss of prdm16, in concordance with the redundant role of Prdm3 and Prdm 16 in various tissues. ${ }^{60,61,62}$ However, both prdm16 morphant and prdm16 crispant zebrafish embryos frequently displayed DAPT-induced AV shunts, indicating that prdm16 signaling controls unique aspects of vascular development that are not shared with other prdm proteins.

Recent evidence suggests that a Sox17-mediated increase of N1ICD levels arterializes ECs. ${ }^{51}$ However, our data indicated that Prdm16 does not alter N1ICD levels, but rather complements Sox17 and amplifies the NICD signaling output by directly binding to NICD. In support of these findings, we did not observe ectopic Notch in the PCV of 
$\operatorname{Tg}(f l i 1 a: m P r d m 16) ; \operatorname{Tg}(T p 1: e G F P)^{u m 14}$ embryos, although the latter displayed significantly higher residual arterial Notch activity compared to $\operatorname{Tg}(T p 1: e G F P)^{u m 14}$ control embryos when challenged with DAPT. The effect of Prdm16 on canonical Notch activity is thus reliant on NICD availability, without a direct effect of Prdm16 on NICD levels per se. Whether Prdm16 and NICD directly bind at the promoter of Notch target genes or complex through intermediate binding partners remains an outstanding question. Intriguingly, hamlet controls chromatin accessibility at Notch loci in drosophila neurogenesis, ${ }^{23}$ suggesting that Prdm16 might amplify NICD signaling within the endothelium by remodeling chromatin at Notch-responsive loci. Finally, additional studies are needed to determine if Prdm16 and Coup-TFII directly compete with each other for binding at the promoter of shared target sites, including the Heyl and Hey2 promoter.

The intricate interplay between Prdm family members and Notch ${ }^{23-25}$ and the direct binding of Prdm proteins to basic helix-loop-helix (bHLH) TFs - a TF family to which HEY2 belongs in various cell types ${ }^{26,27}$ have been extensively described outside the vasculature. Here, we demonstrate that Prdm16 influenced arterial specification and development by physically and functionally interacting with Hey2, in line with previous studies describing interactions between Prdm and bHLH TFs. ${ }^{26,27,63}$ As Prdm16 also boosted HEY2 promoter activity, Prdm16 may activate canonical Notch signaling and drive arterial endothelial specification by potentiating NICD first, to complex with Hey2 to maintain endothelial arterial identity later on. Future studies interrogating the dynamic interplay between Prdm16 and Hey2 would provide key insights into the binary cell fate decisions made by (endothelial) precursors.

Finally, recent GWAS have implicated both PRDM16 and NOTCH in vascular disorders, including migraine ${ }^{64}$ and coronary artery disease ${ }^{65}$, while a recent report suggested a potential role for Prdm16 during coronary artery development. ${ }^{46}$ Hence, our findings documenting the role of 
Prdm16 as a rheostat for arterial endothelial Notch activity may have important clinical implications for vascular disease during development and throughout adulthood. Studies to determine whether Prdm16 is involved in arterial pathologies could therefore provide additional information on its role during these pathophysiological processes and the potential use of therapeutics targeting the Prdm16-Notch axis. 


\section{ACKNOWLEDGMENTS}

The authors thank P. Vandervoort, B. Hoekman and T. Vervoort for technical assistance. We also thank P. Carmeliet for the zebrafish WISH probes and the VIB Nucleomics Core for their help with the whole-genome transcriptomic data analysis.

\section{FUNDING SOURCES}

Research was supported by the European Research Council Starting Grant FP7-StGIMAGINED203291 (A.L.), internal funding from KU Leuven (a Program Financing Grant (PF/10/014; A.L.) and a C1 grant (C14/19/095 to A.L. and M.D.)), a pre-doctoral research fellowship from the 'Agentschap voor Innovatie door Wetenschap en Technologie' (IWT; SB/0881071; M.B.), research grants from the 'Fonds voor Wetenschappelijk Onderzoek Vlaanderen' (FWO; G0B0913N, G0A2214N, and G099521N; A.L.), an FWO Strategic Basic Research pre-doctoral fellowship (1S25817N; J.V.W.), the NIH (5R24OD017870-06; C.M.) and One Brave Idea (414110-68953; C.M.).

\section{DISCLOSURES}

None.

\section{SUPPLEMENTAL MATERIALS}

Expanded materials and methods

Online FiguresI-V

Online TablesI-V

Online MoviesI-XVII 


\section{REFERENCES}

1. Lawson ND, Scheer N, Pham VN, Kim CH, Chitnis AB, Campos-Ortega JA and Weinstein BM. Notch signaling is required for arterial-venous differentiation during embryonic vascular development. Development. 2001;128:3675-83.

2. Quillien A, Moore JC, Shin M, Siekmann AF, Smith T, Pan L, Moens CB, Parsons MJ and Lawson ND. Distinct Notch signaling outputs pattern the developing arterial system. Development. 2014;141:1544-52.

3. Swift MR, Pham VN, Castranova D, Bell K, Poole RJ and Weinstein BM. SoxF factors and Notch regulate nr2f2 gene expression during venous differentiation in zebrafish. Dev Biol. 2014;390:116-25.

4. Weinstein BM, Stemple DL, Driever W and Fishman MC. Gridlock, a localized heritable vascular patterning defect in the zebrafish. Nat Med. 1995;1:1143-7.

5. Zhong TP, Childs S, Leu JP and Fishman MC. Gridlock signalling pathway fashions the first embryonic artery. Nature. 2001;414:216-20.

6. Zhong TP, Rosenberg M, Mohideen MA, Weinstein B and Fishman MC. gridlock, an HLH gene required for assembly of the aorta in zebrafish. Science. 2000;287:1820-4.

7. Fischer A, Schumacher N, Maier M, Sendtner M and Gessler M. The Notch target genes Hey1 and Hey2 are required for embryonic vascular development. Genes Dev. 2004;18:901-11.

8. Gridley T. Notch signaling during vascular development. Proc Natl Acad Sci U S A. 2001;98:5377-8.

9. Krebs LT, Xue Y, Norton CR, Shutter JR, Maguire M, Sundberg JP, Gallahan D, Closson V, Kitajewski J, Callahan R, Smith GH, Stark KL and Gridley T. Notch signaling is essential for vascular morphogenesis in mice. Genes Dev. 2000;14:1343-52.

10. Diez H, Fischer A, Winkler A, Hu CJ, Hatzopoulos AK, Breier G and Gessler M. Hypoxiamediated activation of Dll4-Notch-Hey2 signaling in endothelial progenitor cells and adoption of arterial cell fate. Exp Cell Res. 2007;313:1-9.

11. Korten S, Brunssen C, Poitz DM, Grossklaus S, Brux M, Schnittler HJ, Strasser RH, Bornstein SR, Morawietz H and Goettsch W. Impact of Hey2 and COUP-TFII on genes involved in arteriovenous differentiation in primary human arterial and venous endothelial cells. Basic Res Cardiol. 2013;108:362.

12. Aranguren XL, Beerens M, Coppiello G, Wiese C, Vandersmissen I, Lo Nigro A, Verfaillie CM, Gessler M and Luttun A. COUP-TFII orchestrates venous and lymphatic endothelial identity by homo- or hetero-dimerisation with PROX1. J Cell Sci. 2013;126:1164-75.

13. Aranguren XL, Beerens M, Vandevelde W, Dewerchin M, Carmeliet P and Luttun A. Transcription factor COUP-TFII is indispensable for venous and lymphatic development in zebrafish and Xenopus laevis. Biochem Biophys Res Commun. 2011;410:121-6.

14. You LR, Lin FJ, Lee CT, DeMayo FJ, Tsai MJ and Tsai SY. Suppression of Notch signalling by the COUP-TFII transcription factor regulates vein identity. Nature. 2005;435:98104.

15. Davis RB, Pahl K, Datto NC, Smith SV, Shawber C, Caron KM and Blatt J. Notch signaling pathway is a potential therapeutic target for extracranial vascular malformations. Sci Rep. 2018;8:17987.

16. Delev D, Pavlova A, Grote A, Bostrom A, Hollig A, Schramm J, Fimmers R, Oldenburg J and Simon M. NOTCH4 gene polymorphisms as potential risk factors for brain arteriovenous malformation development and hemorrhagic presentation. J Neurosurg. 2017;126:1552-1559. 
17. Hill-Felberg S, Wu HH, Toms SA and Dehdashti AR. Notch receptor expression in human brain arteriovenous malformations. J Cell Mol Med. 2015;19:1986-93.

18. Kajimura S, Seale P, Tomaru T, Erdjument-Bromage H, Cooper MP, Ruas JL, Chin S, Tempst P, Lazar MA and Spiegelman BM. Regulation of the brown and white fat gene programs through a PRDM16/CtBP transcriptional complex. Genes Dev. 2008;22:1397-409.

19. Seale P, Kajimura S, Yang W, Chin S, Rohas LM, Uldry M, Tavernier G, Langin D and Spiegelman BM. Transcriptional control of brown fat determination by PRDM16. Cell Metab. 2007;6:38-54.

20. Li L, Xie X, Qin J, Jeha GS, Saha PK, Yan J, Haueter CM, Chan L, Tsai SY and Tsai MJ. The nuclear orphan receptor COUP-TFII plays an essential role in adipogenesis, glucose homeostasis, and energy metabolism. Cell Metab. 2009;9:77-87.

21. Aranguren XL, Agirre X, Beerens M, Coppiello G, Uriz M, Vandersmissen I, Benkheil M, Panadero J, Aguado N, Pascual-Montano A, Segura V, Prosper F and Luttun A. Unraveling a novel transcription factor code determining the human arterial-specific endothelial cell signature. Blood. 2013;122:3982-92.

22. Sissaoui S, Yu J, Yan A, Li R, Yukselen O, Kucukural A, Zhu LJ and Lawson ND. Genomic Characterization of Endothelial Enhancers Reveals a Multifunctional Role for NR2F2 in Regulation of Arteriovenous Gene Expression. Circ Res. 2020;126:875-888.

23. Endo K, Aoki T, Yoda Y, Kimura K and Hama C. Notch signal organizes the Drosophila olfactory circuitry by diversifying the sensory neuronal lineages. Nat Neurosci. 2007;10:153-60.

24. Kinameri E, Inoue T, Aruga J, Imayoshi I, Kageyama R, Shimogori T and Moore AW. Prdm proto-oncogene transcription factor family expression and interaction with the Notch-Hes pathway in mouse neurogenesis. PLoS One. 2008;3:e3859.

25. Li Y, Cheng CN, Verdun VA and Wingert RA. Zebrafish nephrogenesis is regulated by interactions between retinoic acid, mecom, and Notch signaling. Dev Biol. 2014;386:111-22.

26. Mona B, Uruena A, Kollipara RK, Ma Z, Borromeo MD, Chang JC and Johnson JE. Repression by PRDM13 is critical for generating precision in neuronal identity. Elife. 2017;6.

27. Ross SE, McCord AE, Jung C, Atan D, Mok SI, Hemberg M, Kim TK, Salogiannis J, Hu L, Cohen S, Lin Y, Harrar D, McInnes RR and Greenberg ME. Bhlhb5 and Prdm8 form a repressor complex involved in neuronal circuit assembly. Neuron. 2012;73:292-303.

28. Motoike T, Loughna S, Perens E, Roman BL, Liao W, Chau TC, Richardson CD, Kawate T, Kuno J, Weinstein BM, Stainier DY and Sato TN. Universal GFP reporter for the study of vascular development. Genesis. 2000;28:75-81.

29. Bjork BC, Turbe-Doan A, Prysak M, Herron BJ and Beier DR. Prdm16 is required for normal palatogenesis in mice. Hum Mol Genet. 2010;19:774-89.

30. Arndt AK, Schafer S, Drenckhahn JD, Sabeh MK, Plovie ER, Caliebe A, Klopocki E, Musso G, Werdich AA, Kalwa H, Heinig M, Padera RF, Wassilew K, Bluhm J, Harnack C, Martitz J, Barton PJ, Greutmann M, Berger F, Hubner N, Siebert R, Kramer HH, Cook SA, MacRae CA and Klaassen S. Fine mapping of the 1p36 deletion syndrome identifies mutation of PRDM16 as a cause of cardiomyopathy. Am J Hum Genet. 2013;93:67-77.

31. Jungke P, Hammer J, Hans S and Brand M. Isolation of Novel CreERT2-Driver Lines in Zebrafish Using an Unbiased Gene Trap Approach. PLoS One. 2015;10:e0129072.

32. Matrone G, Xia B, Chen K, Denvir MA, Baker AH and Cooke JP. Fli1(+) cells transcriptional analysis reveals an Lmo2-Prdm16 axis in angiogenesis. Proc Natl Acad Sci US A. $2021 ; 118$. 
33. Nam JM, Lim JE, Ha TW, Oh B and Kang JO. Cardiac-specific inactivation of Prdm16 effects cardiac conduction abnormalities and cardiomyopathy-associated phenotypes. Am $\mathrm{J}$ Physiol Heart Circ Physiol. 2020;318:H764-H777.

34. Buschmann I, Pries A, Styp-Rekowska B, Hillmeister P, Loufrani L, Henrion D, Shi Y, Duelsner A, Hoefer I, Gatzke N, Wang H, Lehmann K, Ulm L, Ritter Z, Hauff P, Hlushchuk R, Djonov V, van Veen $\mathrm{T}$ and le Noble F. Pulsatile shear and Gja5 modulate arterial identity and remodeling events during flow-driven arteriogenesis. Development. 2010;137:2187-96.

35. Fang JS, Coon BG, Gillis N, Chen Z, Qiu J, Chittenden TW, Burt JM, Schwartz MA and Hirschi KK. Shear-induced Notch-Cx37-p27 axis arrests endothelial cell cycle to enable arterial specification. Nat Commun. 2017;8:2149.

36. Parsons MJ, Pisharath H, Yusuff S, Moore JC, Siekmann AF, Lawson N and Leach SD. Notch-responsive cells initiate the secondary transition in larval zebrafish pancreas. Mech Dev. 2009;126:898-912.

37. Duarte A, Hirashima M, Benedito R, Trindade A, Diniz P, Bekman E, Costa L, Henrique $\mathrm{D}$ and Rossant J. Dosage-sensitive requirement for mouse D1l4 in artery development. Genes Dev. 2004;18:2474-8.

38. Gale NW, Dominguez MG, Noguera I, Pan L, Hughes V, Valenzuela DM, Murphy AJ, Adams NC, Lin HC, Holash J, Thurston G and Yancopoulos GD. Haploinsufficiency of delta-like 4 ligand results in embryonic lethality due to major defects in arterial and vascular development. Proc Natl Acad Sci U S A. 2004;101:15949-54.

39. Krebs LT, Shutter JR, Tanigaki K, Honjo T, Stark KL and Gridley T. Haploinsufficient lethality and formation of arteriovenous malformations in Notch pathway mutants. Genes Dev. 2004;18:2469-73.

40. Wu RS, Lam, II, Clay H, Duong DN, Deo RC and Coughlin SR. A Rapid Method for Directed Gene Knockout for Screening in G0 Zebrafish. Dev Cell. 2018;46:112-125 e4.

41. Nielsen CM, Cuervo H, Ding VW, Kong Y, Huang EJ and Wang RA. Deletion of Rbpj from postnatal endothelium leads to abnormal arteriovenous shunting in mice. Development. 2014;141:3782-92.

42. Wythe JD, Dang LT, Devine WP, Boudreau E, Artap ST, He D, Schachterle W, Stainier DY, Oettgen P, Black BL, Bruneau BG and Fish JE. ETS factors regulate Vegf-dependent arterial specification. Dev Cell. 2013;26:45-58.

43. Lacorre DA, Baekkevold ES, Garrido I, Brandtzaeg P, Haraldsen G, Amalric F and Girard JP. Plasticity of endothelial cells: rapid dedifferentiation of freshly isolated high endothelial venule endothelial cells outside the lymphoid tissue microenvironment. Blood. 2004;103:4164-72.

44. Sabbagh MF and Nathans J. A genome-wide view of the de-differentiation of central nervous system endothelial cells in culture. Elife. 2020;9.

45. Wick N, Saharinen P, Saharinen J, Gurnhofer E, Steiner CW, Raab I, Stokic D, Giovanoli P, Buchsbaum S, Burchard A, Thurner S, Alitalo K and Kerjaschki D. Transcriptomal comparison of human dermal lymphatic endothelial cells ex vivo and in vitro. Physiol Genomics. 2007;28:17992.

46. Ragini Phansalkar JK, Mingming Zhao, Sai Saroja Kolluru, Robert C. Jones, Stephen R Quake, Irving Weissman, Daniel Bernstein, Virginia D. Winn, Gaetano D’Amato, Kristy RedHorse. Coronary blood vessels from distinct origins converge to equivalent states during mouse and human development. 2021.

47. Craps S, Van Wauwe J, De Moudt S, De Munck D, Leloup AJA, Boeckx B, Vervliet T, Dheedene W, Criem N, Geeroms C, Jones EAV, Zwijsen A, Lambrechts D, Fransen P, Beerens 
M and Luttun A. Prdm16 Supports Arterial Flow Recovery by Maintaining Endothelial Function. Circulation research. 2021;129:63-77.

48. Shutter JR, Scully S, Fan W, Richards WG, Kitajewski J, Deblandre GA, Kintner CR and Stark KL. D114, a novel Notch ligand expressed in arterial endothelium. Genes Dev. 2000;14:13138.

49. Hayashi $\mathrm{H}$ and Kume T. Foxc transcription factors directly regulate D114 and Hey2 expression by interacting with the VEGF-Notch signaling pathways in endothelial cells. PLoS One. 2008;3:e2401.

50. Seo S, Fujita H, Nakano A, Kang M, Duarte A and Kume T. The forkhead transcription factors, Foxc1 and Foxc2, are required for arterial specification and lymphatic sprouting during vascular development. Dev Biol. 2006;294:458-70.

51. Corada M, Orsenigo F, Morini MF, Pitulescu ME, Bhat G, Nyqvist D, Breviario F, Conti V, Briot A, Iruela-Arispe ML, Adams RH and Dejana E. Sox17 is indispensable for acquisition and maintenance of arterial identity. Nat Commun. 2013;4:2609.

52. Hermkens DM, van Impel A, Urasaki A, Bussmann J, Duckers HJ and Schulte-Merker S. Sox7 controls arterial specification in conjunction with hey2 and efnb2 function. Development. 2015;142:1695-704.

53. Carlson TR, Yan Y, Wu X, Lam MT, Tang GL, Beverly LJ, Messina LM, Capobianco AJ, Werb $\mathrm{Z}$ and Wang R. Endothelial expression of constitutively active Notch4 elicits reversible arteriovenous malformations in adult mice. Proc Natl Acad Sci U S A. 2005;102:9884-9.

54. Krebs LT, Starling C, Chervonsky AV and Gridley T. Notch1 activation in mice causes arteriovenous malformations phenocopied by ephrinB2 and EphB4 mutants. Genesis. 2010;48:146-50.

55. Murphy PA, Kim TN, Huang L, Nielsen CM, Lawton MT, Adams RH, Schaffer CB and Wang RA. Constitutively active Notch4 receptor elicits brain arteriovenous malformations through enlargement of capillary-like vessels. Proc Natl Acad Sci U S A. 2014;111:18007-12.

56. Trindade A, Kumar SR, Scehnet JS, Lopes-da-Costa L, Becker J, Jiang W, Liu R, Gill PS and Duarte A. Overexpression of delta-like 4 induces arterialization and attenuates vessel formation in developing mouse embryos. Blood. 2008;112:1720-9.

57. Uyttendaele H, Ho J, Rossant J and Kitajewski J. Vascular patterning defects associated with expression of activated Notch4 in embryonic endothelium. Proc Natl Acad Sci U S A. 2001;98:5643-8.

58. Konantz M, Alghisi E, Muller JS, Lenard A, Esain V, Carroll KJ, Kanz L, North TE and Lengerke C. Evil regulates Notch activation to induce zebrafish hematopoietic stem cell emergence. EMBO J. 2016;35:2315-2331.

59. Bi P and Kuang $\mathrm{S}$. Notch signaling as a novel regulator of metabolism. Trends Endocrinol Metab. 2015;26:248-55.

60. Pinheiro I, Margueron R, Shukeir N, Eisold M, Fritzsch C, Richter FM, Mittler G, Genoud C, Goyama S, Kurokawa M, Son J, Reinberg D, Lachner M and Jenuwein T. Prdm3 and Prdm16 are $\mathrm{H} 3 \mathrm{~K} 9 \mathrm{me}$ methyltransferases required for mammalian heterochromatin integrity. Cell. 2012;150:948-60.

61. Ding HL, Clouthier DE and Artinger KB. Redundant roles of PRDM family members in zebrafish craniofacial development. Dev Dyn. 2013;242:67-79.

62. Harms MJ, Ishibashi J, Wang W, Lim HW, Goyama S, Sato T, Kurokawa M, Won KJ and Seale P. Prdm16 is required for the maintenance of brown adipocyte identity and function in adult mice. Cell Metab. 2014;19:593-604. 
63. Yildiz O, Downes GB and Sagerstrom CG. Zebrafish prdm12b acts independently of nkx6.1 repression to promote eng1b expression in the neural tube p1 domain. Neural Dev. 2019;14:5.

64. Gormley P, Anttila V, Winsvold BS, Palta P, Esko T, Pers TH, Farh KH, Cuenca-Leon E, Muona M, Furlotte NA, Kurth T, Ingason A, McMahon G, Ligthart L, Terwindt GM, Kallela M, Freilinger TM, Ran C, Gordon SG, Stam AH, Steinberg S, Borck G, Koiranen M, Quaye L, Adams HH, Lehtimaki T, Sarin AP, Wedenoja J, Hinds DA, Buring JE, Schurks M, Ridker PM, Hrafnsdottir MG, Stefansson H, Ring SM, Hottenga JJ, Penninx BW, Farkkila M, Artto V, Kaunisto M, Vepsalainen S, Malik R, Heath AC, Madden PA, Martin NG, Montgomery GW, Kurki MI, Kals M, Magi R, Parn K, Hamalainen E, Huang H, Byrnes AE, Franke L, Huang J, Stergiakouli E, Lee PH, Sandor C, Webber C, Cader Z, Muller-Myhsok B, Schreiber S, Meitinger T, Eriksson JG, Salomaa V, Heikkila K, Loehrer E, Uitterlinden AG, Hofman A, van Duijn CM, Cherkas L, Pedersen LM, Stubhaug A, Nielsen CS, Mannikko M, Mihailov E, Milani L, Gobel H, Esserlind AL, Christensen AF, Hansen TF, Werge T, International Headache Genetics C, Kaprio J, Aromaa AJ, Raitakari O, Ikram MA, Spector T, Jarvelin MR, Metspalu A, Kubisch C, Strachan DP, Ferrari MD, Belin AC, Dichgans M, Wessman M, van den Maagdenberg AM, Zwart JA, Boomsma DI, Smith GD, Stefansson K, Eriksson N, Daly MJ, Neale BM, Olesen J, Chasman DI, Nyholt DR and Palotie A. Meta-analysis of 375,000 individuals identifies 38 susceptibility loci for migraine. Nat Genet. 2016;48:856-66.

65. van der Harst $P$ and Verweij N. Identification of 64 Novel Genetic Loci Provides an Expanded View on the Genetic Architecture of Coronary Artery Disease. Circ Res. 2018;122:433443. 
bioRxiv preprint doi: https://doi.org/10.1101/2021.12.05.471275; this version posted December 16,2021 . The copyright holder for this preprint

(which was not certified by peer review) is the author/funder, who has granted bioRxiv a license to display the preprint in perpetuity. It is made available under aCC-BY-NC-ND 4.0 International license.

\section{FIGURES AND LEGENDS}

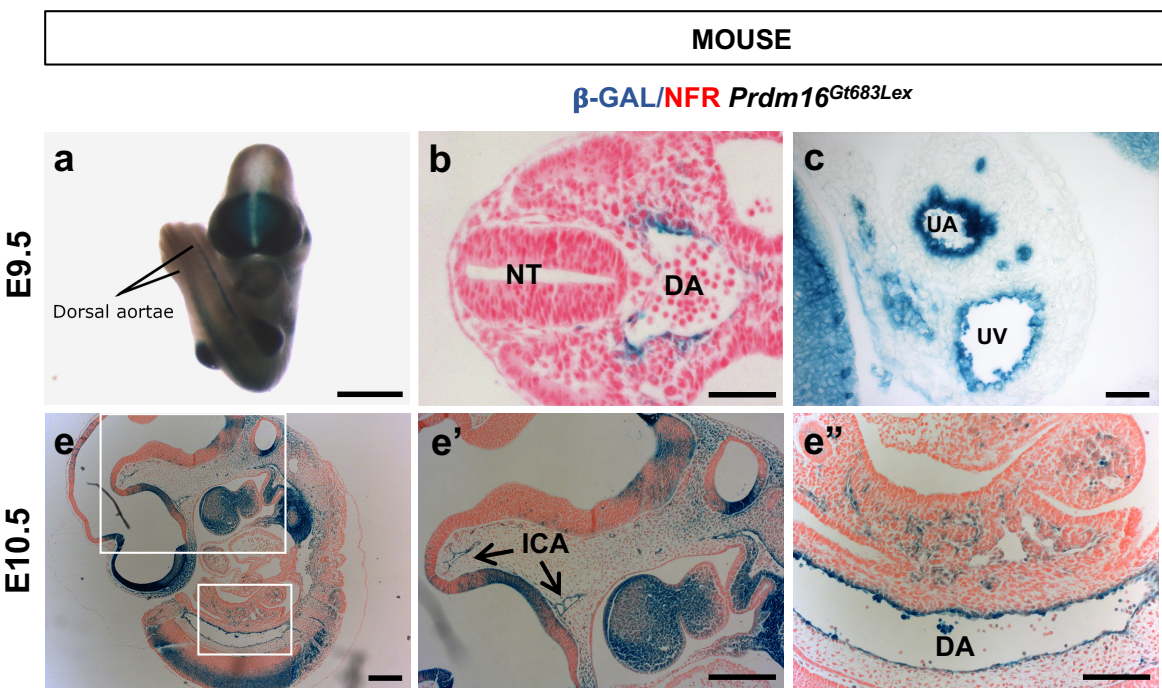

IF:Prdm16/aSMA/DAPI
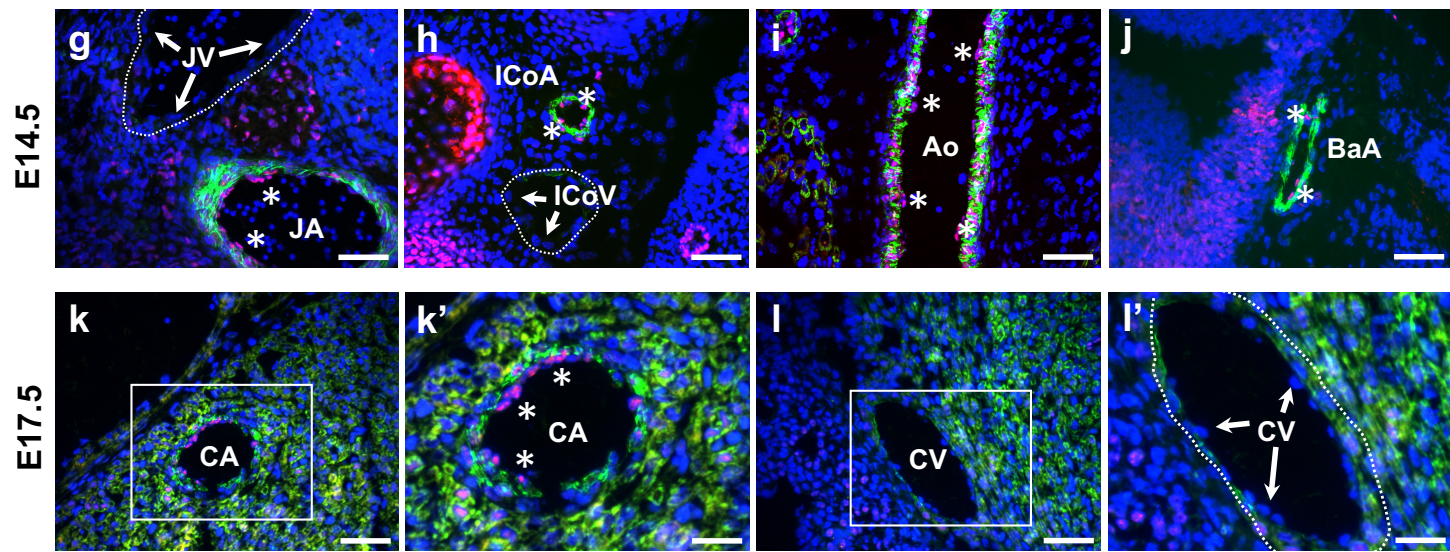

HUMAN

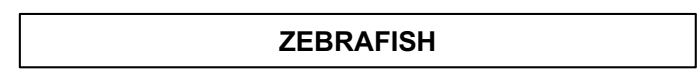

IF:Prdm16/oSMA/DAPI

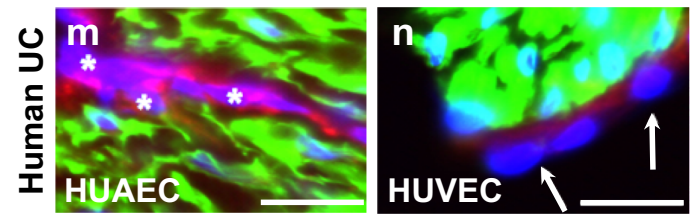

prdm16:Cre ${ }^{E R T 2}$-P2A-dsRed (tud28Gt) ubi:switch
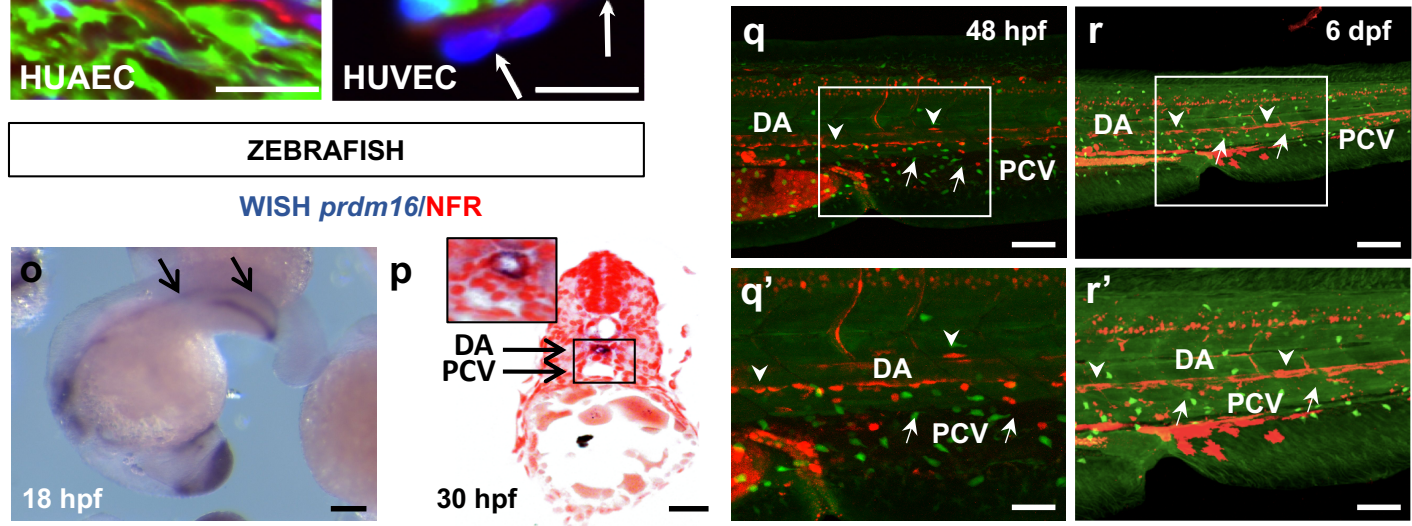
Figure 1. Prdm16 displays an arterial-specific expression profile in mammals and zebrafish.

(a-h) Whole embryo view $(a)$, cross-sections $(b-d)$ or sagittal sections $(e-h)$ of $\beta$-galactosidase $(\beta$ GAL) activity staining on embryonic day (E)9.5 (a-d) or E10.5 (e-f) embryos of the Prdm16 reporter mouse strain $\left(\operatorname{Prdm} 16^{\text {Gt683Lex }}\right)$. NFR counterstaining was used in $b, d-f$. NT: neural tube; DA: dorsal aorta; UA: umbilical artery; UV: umbilical vein; VA: vitelline artery; VV: vitelline vein; ICA: intracranial artery; ISV: intersomitic vessel. (g-n) Immunofluorescence (IF) staining for Prdm16 (magenta), $\alpha$-smooth muscle actin ( $\alpha$ SMA; green) and cell nuclei (DAPI; blue) on cross-sections of E14.5 ( $g-j)$ or E17.5 ( $\left.k-l^{\prime}\right)$ FvB mouse embryos or human umbilical cord $(m, n)$. Asterisks indicate Prdm16-expressing arterial ECs, white arrows Prdm16-negative venous ECs. Veins are lined with white dotted lines in $g, h, l$ '. JA: jugular artery; JV: jugular vein; ICoA: intercostal artery; ICoV: intercostal vein; Ao: aorta; BaA: basilar artery; CA: coronary artery; CV: coronary vein; HUAEC: human umbilical artery endothelial cell; HUVEC: human umbilical vein endothelial cell. (o) WISH for prdm16 in an $18 \mathrm{hpf}$ zebrafish embryo. Black arrows indicate prdm16 expression in the DA. (p) Cross-section of a 30 hpf zebrafish embryo after WISH for prdm16 counter-stained with NFR. PCV: posterior cardinal vein. (q-r') Confocal images of tud28Gt zebrafish embryos, reporting prdm16 activity (red) crossed with ubi:switch (green) embryos for better contrast. The DA (white arrowheads), but not the PCV (white arrows) expresses $\operatorname{prdm} 16$ at $48 \mathrm{hpf}\left(q, q^{\prime}\right)$ and $6 \mathrm{dpf}\left(r, r^{\prime}\right)$. Panels labeled with' represent insets. Scale bars: $1 \mathrm{~mm}$ in $a ; 200 \mu \mathrm{m}$ in $o ; 100 \mu \mathrm{m}$ in $b, e-f, o, p ; 50 \mu \mathrm{m}$ in $g-l, q, q^{\prime}, r, r^{\prime} ; 25 \mu \mathrm{m}$ in $k^{\prime}, l^{\prime}, p$. 
nc Mo

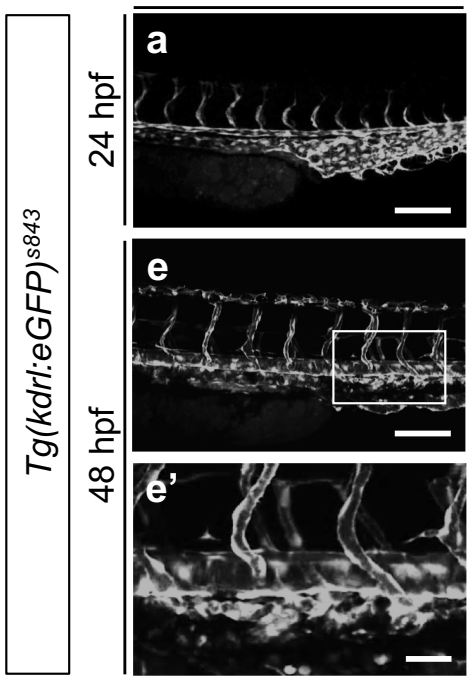

i

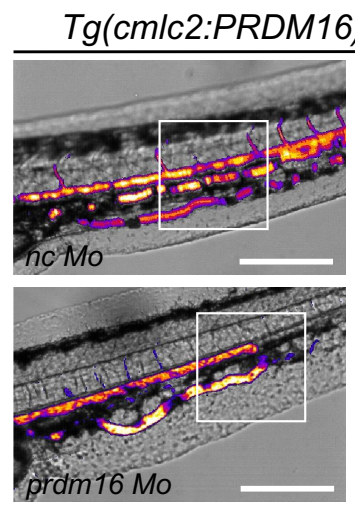

pram $16 \mathrm{Mo}$
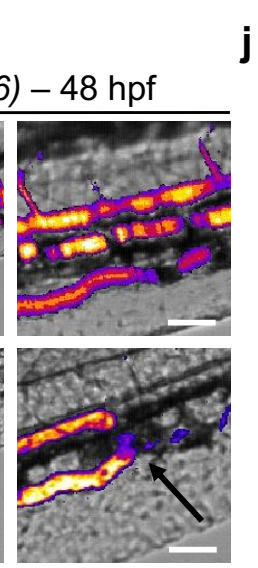

prdm16 Mo
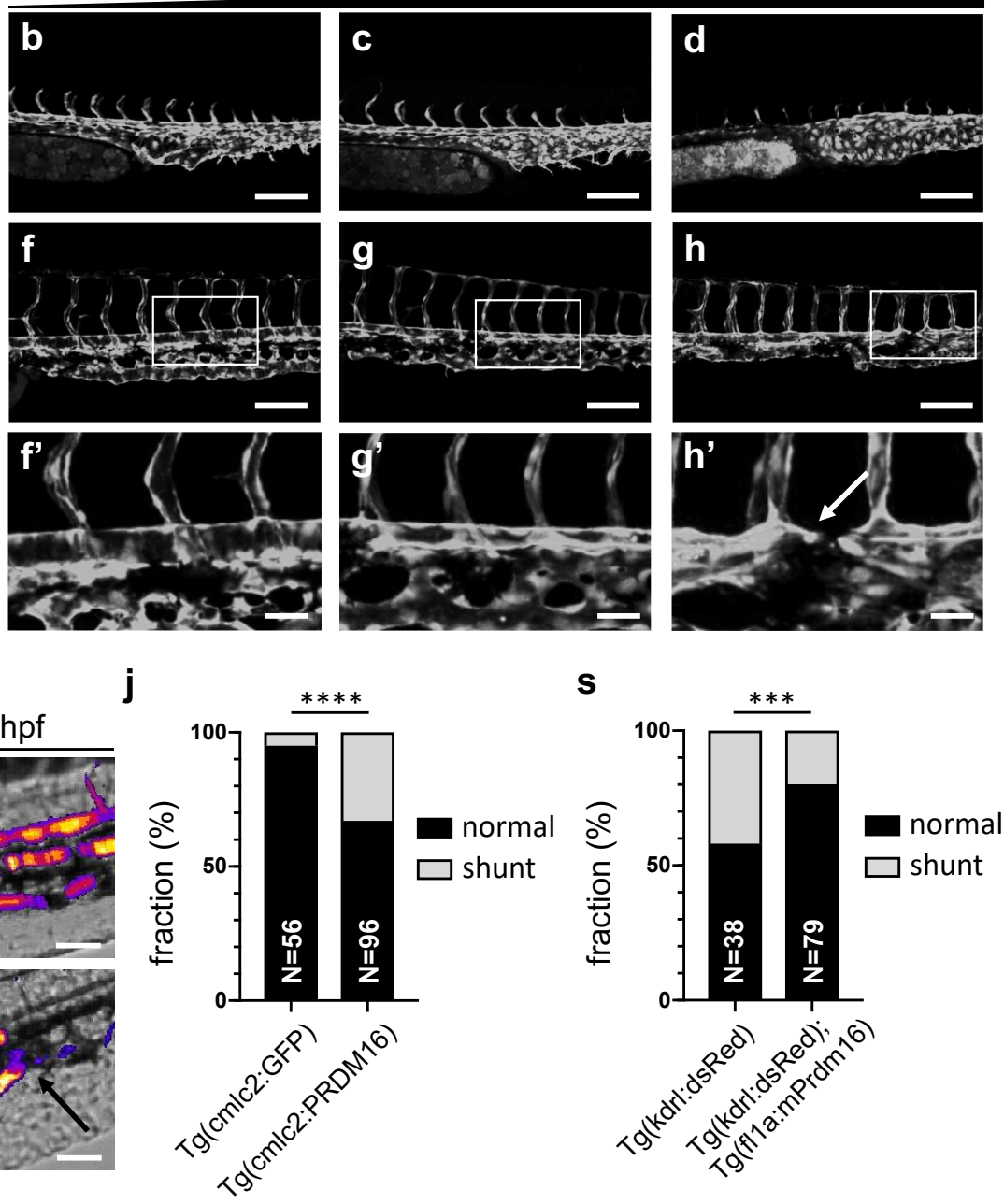

prdm16 Mo

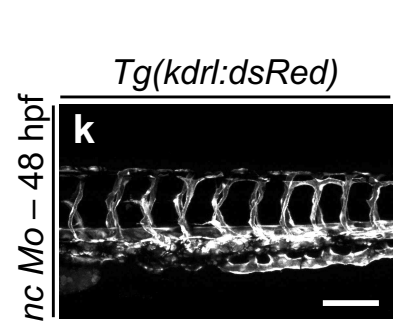

\section{$\operatorname{Tg}(k d r l: d s R e d)$} Tg(fli1a:mPrdm16)
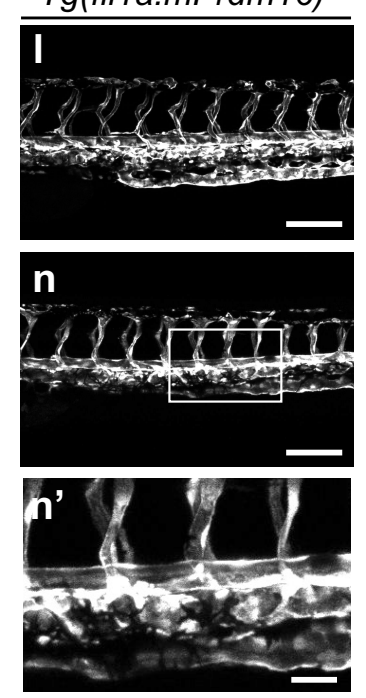
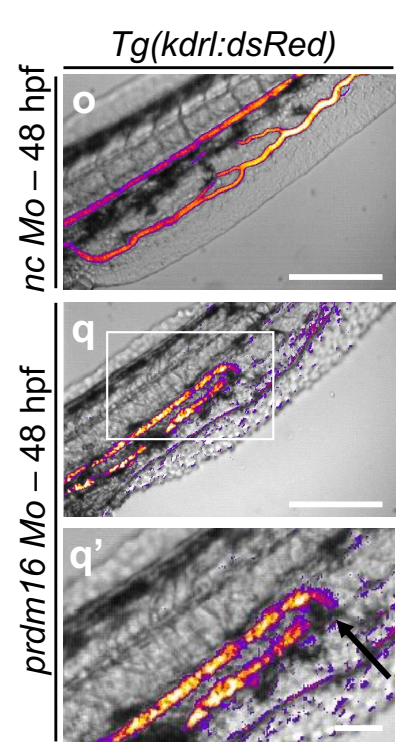

$T g(k d r l: d s R e d)$;
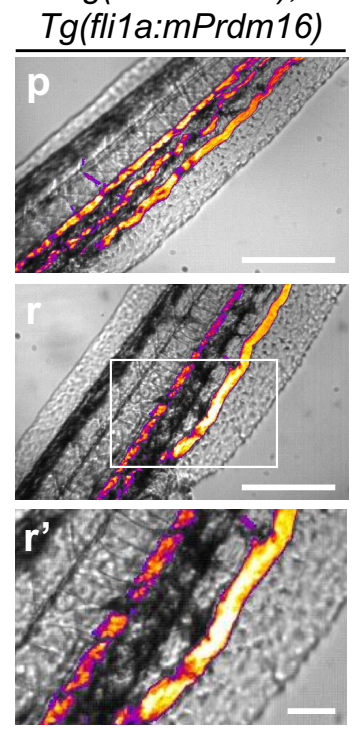
Figure 2. prdm16 deficiency leads to vascular defects in an EC-autonomous manner. (a-h') Confocal images of $\operatorname{Tg}(k d r l: e G F P)^{s 843}$ embryos injected with negative control $(n c)$ or increasing amounts of prdm16 Mo, evaluated at $24(a-d)$ or $48 \mathrm{hpf}\left(e-h^{\prime}\right)$. (i) Angiograms of $48 \mathrm{hpf}$ $\operatorname{Tg}(\mathrm{cmlc2}: P R D M 16)$ zebrafish larvae injected with $n c$ Mo (upper panels) or a high-dose of prdm16 Mo (lower panels). $\operatorname{Tg}(\mathrm{cmlc2}: \mathrm{PRDM16})$ prdm16 morphants frequently displayed AV shunts (black arrow in lower right). (j) Quantification of $\mathrm{AV}$ shunting in $\operatorname{Tg}(\mathrm{cmlc} 2: G F P)$ and $\operatorname{Tg}(\mathrm{cmlc2}: P R D M 16)$ zebrafish embryos injected with high-dose prdm16 Mo. (k-r') Confocal images $\left(k-n^{\prime}\right)$ and angiograms $\left(o-r^{\prime}\right)$ of 48 hpf $T g(k d r l: d s R e d)$ (left panels) and Tg(kdrl:dsRed;flila:mPrdm16) (right panels) embryos injected with $n c$ Mo (upper panels) or highdose $\operatorname{prdm} 16 \mathrm{Mo}$ (middle+lower panels). $\operatorname{prdm} 16$ deficiency in $T g(k d r l: d s R e d)$ resulted in vascular abnormalities with apparent coarctation of the DA (white arrow in $m$ ') and AV shunts (black arrow in $\left.q^{\prime}\right)$. (s) Quantification of AV shunting in $\operatorname{prdm} 16$ morphant $\operatorname{Tg}(k d r l: d s R e d)$ and $\operatorname{Tg}(k d r l: d s R e d$; flila:mPrdm16) zebrafish embryos at 48 hpf. Panels labeled with' represent insets. ${ }^{* * *} P<0.001$; $* * * * P<0.0001$ by Chi square test. Scale bars: $100 \mu \mathrm{m}$ in $a-i, k-n, o-r^{\prime} ; 25 \mu \mathrm{m}$ in $e^{\prime}-h^{\prime}, m^{\prime}, n^{\prime}$. 
a

BOECS

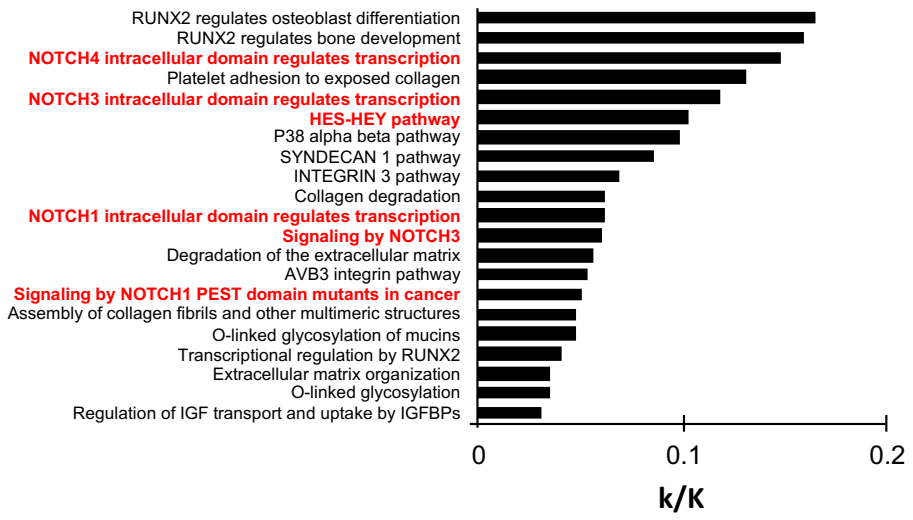

C

HUVECS

Cherry $\square$ mPrdm16

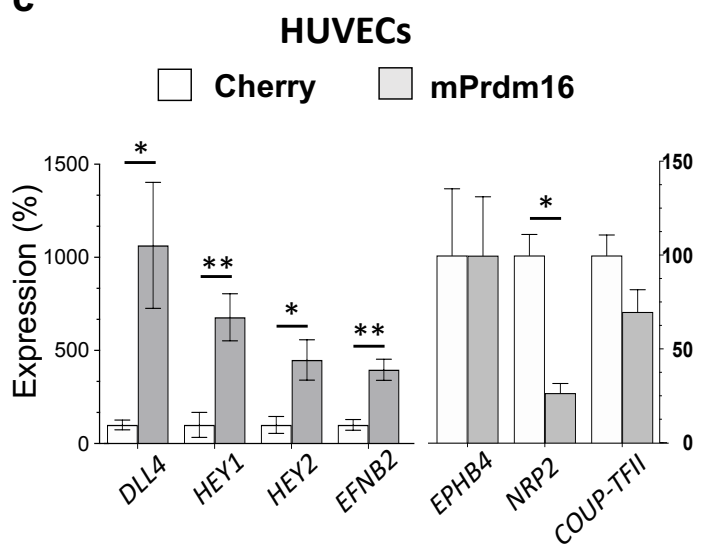

d

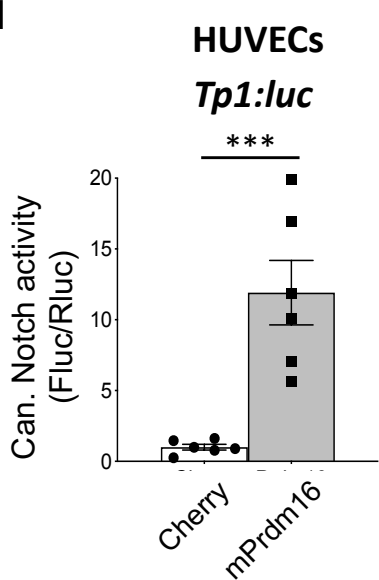

b

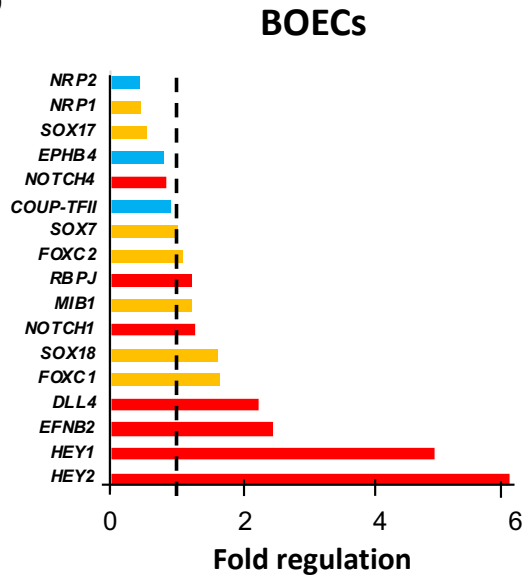

f

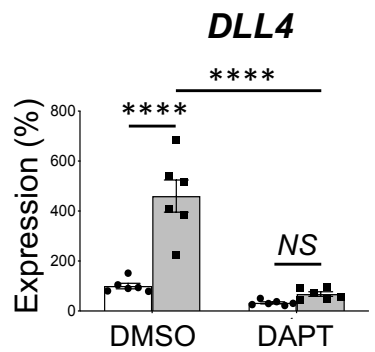

g
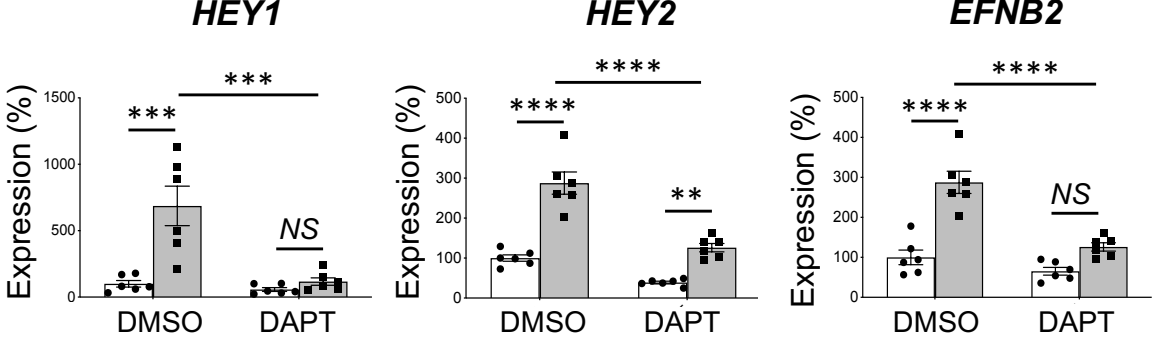

BOECS

Cherry $\square$ mPrdm16
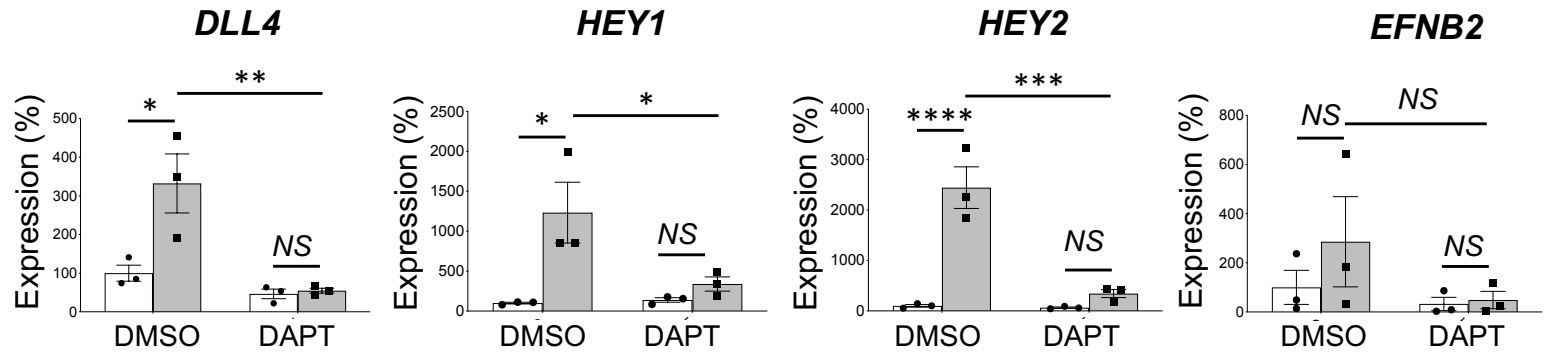
Figure 3. Prdm16 regulates canonical NOTCH activity in human ECs. (a) GSEA for canonical pathways enriched in genes differentially expressed between Prdm 16 overexpressing ('mPrdm16') and control ('Cherry') blood outgrowth endothelial cells (BOECs; N=3). NOTCH-related biological pathways are highlighted in red. (b) Diagram showing the fold regulation as determined by microarray analysis in mPrdm16 vs. Cherry BOECs $(\mathrm{N}=3)$ of select NOTCH pathway members known to be important for arterial development and of venous markers. Red and orange mark classical canonical Notch pathway members or Notch modifiers, respectively, while blue marks venous-specific genes. (c) qRT-PCR mRNA analysis (N=5) for DLL4, HEY1, HEY2 and EFNB2 and the venous markers EPHB4, NRP2 and COUP-TFII in Cherry (white bars) vs. mPrdm16 (gray bars) human umbilical venous ECs (HUVECs). (d,e) Ratiometric Firefly/Renilla-based assay for canonical (can.) NOTCH activity in Cherry+ (white bars) vs. mPrdm16 (gray bars) HUVECs (d, $\mathrm{N}=6)$ and BOECs $(e, \mathrm{~N}=7)$. (f,g) qRT-PCR mRNA analysis for DLL4, HEY1, HEY2 and EFNB2 in Cherry (white bars) or mPrdm16 (gray bars) HUVECs $(f, \mathrm{~N}=6)$ and BOECs $(g, \mathrm{~N}=3)$ treated with DMSO or the canonical NOTCH inhibitor DAPT. $* P<0.05 ; * * P<0.01 ; * * * P<0.001$; $* * * * P<0.0001$; NS: not significant by paired Student's $t$-test $(c-e)$ or 2 -way $\operatorname{ANOVA}(f, g)$. 

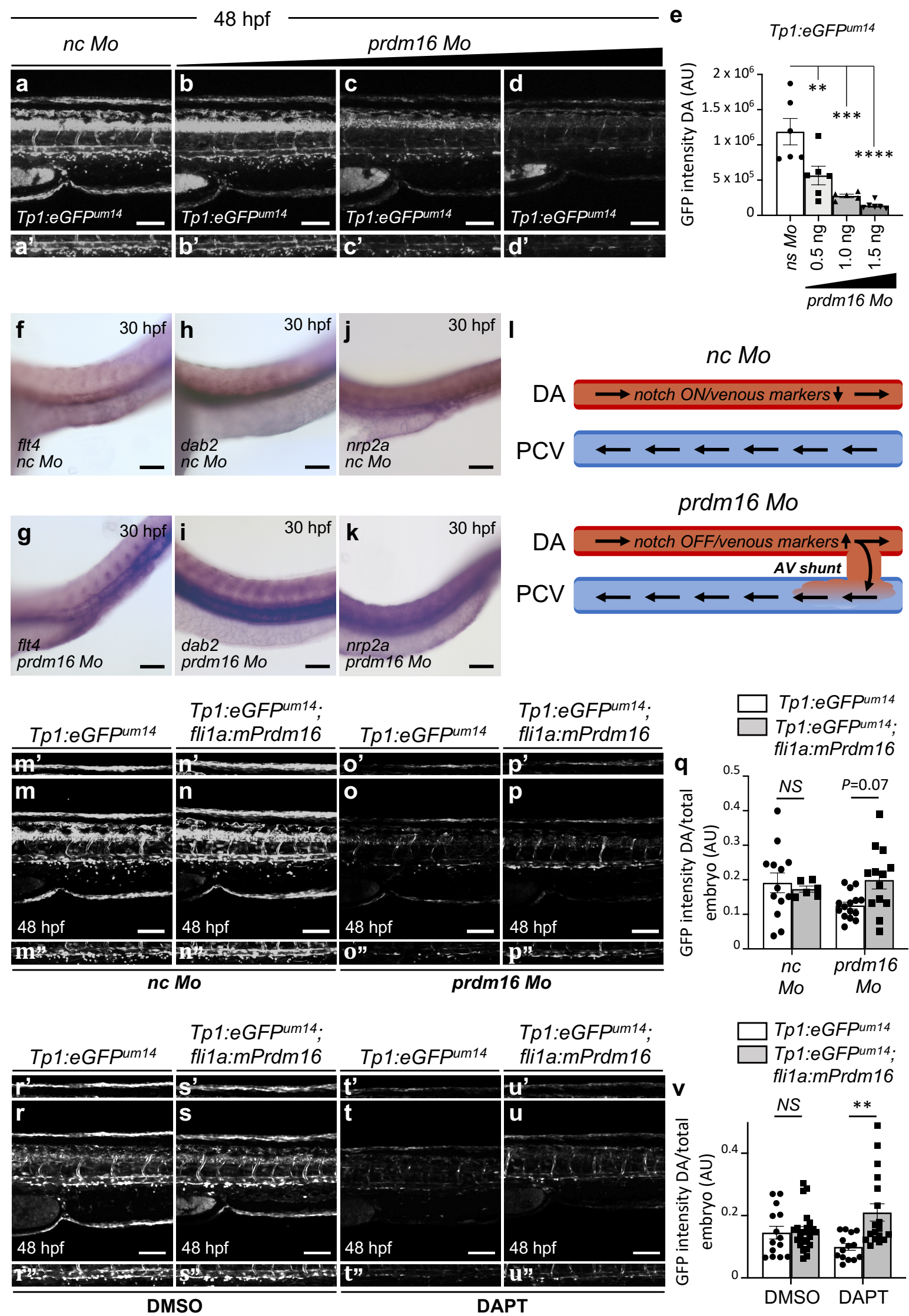


\section{Figure 4. prdm16 drives proper AV endothelial specification during zebrafish}

embryogenesis. (a-e) Confocal images of $48 \mathrm{hpf} \operatorname{Tg}(T p 1: e G F P)^{u m 14}$ zebrafish embryos treated with control morpholino ( $n c \mathrm{Mo} ; a)$ or increasing doses of prdm 16 Mo $(b-d)$ and corresponding quantification (e) of canonical notch activity (GFP intensity, N=5-6) in the dorsal aorta (DA; shown separately in $\left.a^{\prime}-d^{\prime}\right)$ of control (black bar) and prdm16 Mo-injected $\operatorname{Tg}(\operatorname{Tp} 1: e G F P)^{u m 14}$ embryos (gray bars). (f-k) WISH for the venous markers $f l t 4(f, g)$, dab2 $(h, i)$ and $n r p 2 a(j, k)$ in control $(f, h, j)$ and prdm16 morphant $(g, i, k)$ embryos at $30 \mathrm{hpf}$. (l) Schematic overview of the perturbed arteriovenous endothelial specification and AV shunting in prdm16 morphants vs. control embryos. (m-q) Confocal images of $48 \mathrm{hpf} \operatorname{Tg}(\operatorname{Tp} 1: e G F P)^{u m 14} \quad(m, o)$ and $\operatorname{Tg}\left((T p 1: e G F P)^{u m 14} ;\right.$ flila:mPrdm16) (n,p) embryos injected with subthreshold dose of $n c(m, n)$ or $\operatorname{prdm} 16 \mathrm{Mo}(o, p)$ and corresponding ratiometric quantification $(q)$ of canonical notch activity (GFP intensity, $\mathrm{N}=6-13$ ) in the DA (shown separately in $m$ "- $-p$ ") relative to the total embryo of $\operatorname{Tg}(T p 1: e G F P)^{u m 14}$ (white bars) and $\operatorname{Tg}\left((T p 1: e G F P)^{u m 14}\right.$;flila:mPrdm16) (black bars) embryos injected with $n c$ or $p r d m 16$ Mo. Note that prdm16 Mo knockdown caused a similar reduction of GFP signal in non-endothelial tissue (including the dorsal fin fold shown separately in $\left.m^{\prime}-p^{\prime}\right)$. (rv) Confocal images of $48 \mathrm{hpf} \operatorname{Tg}(T p 1: e G F P)^{u m 14}(r, t)$ and $\operatorname{Tg}\left((T p 1: e G F P)^{u m 14}\right.$;flila:mPrdm16) $(s, u)$ embryos treated with DMSO $(r, s)$ or DAPT $(t, u)$ and corresponding ratiometric quantification (v) of canonical notch activity (GFP intensity, $\mathrm{N}=14-23$ ) in the DA (shown separately in $r$ "' $u$ ") relative to the total embryo of $\operatorname{Tg}(T p 1: e G F P)^{u m 14}$ (white bars) and $T g\left((T p 1: e G F P)^{u m 14}\right.$;flila:mPrdm16) (black bars) embryos treated with DMSO or DAPT. Note that DAPT caused a similar reduction of GFP signal in non-endothelial tissue (including the dorsal fin fold shown separately in $\left.r^{\prime}-u^{\prime}\right) .{ }^{* *} P<0.01$; $* * * P<0.001$; $* * * * P<0.0001$; NS: not significant by one-way $(e)$ or 2-way ANOVA $(q, v)$. Scale bars: $100 \mu \mathrm{m}$. 


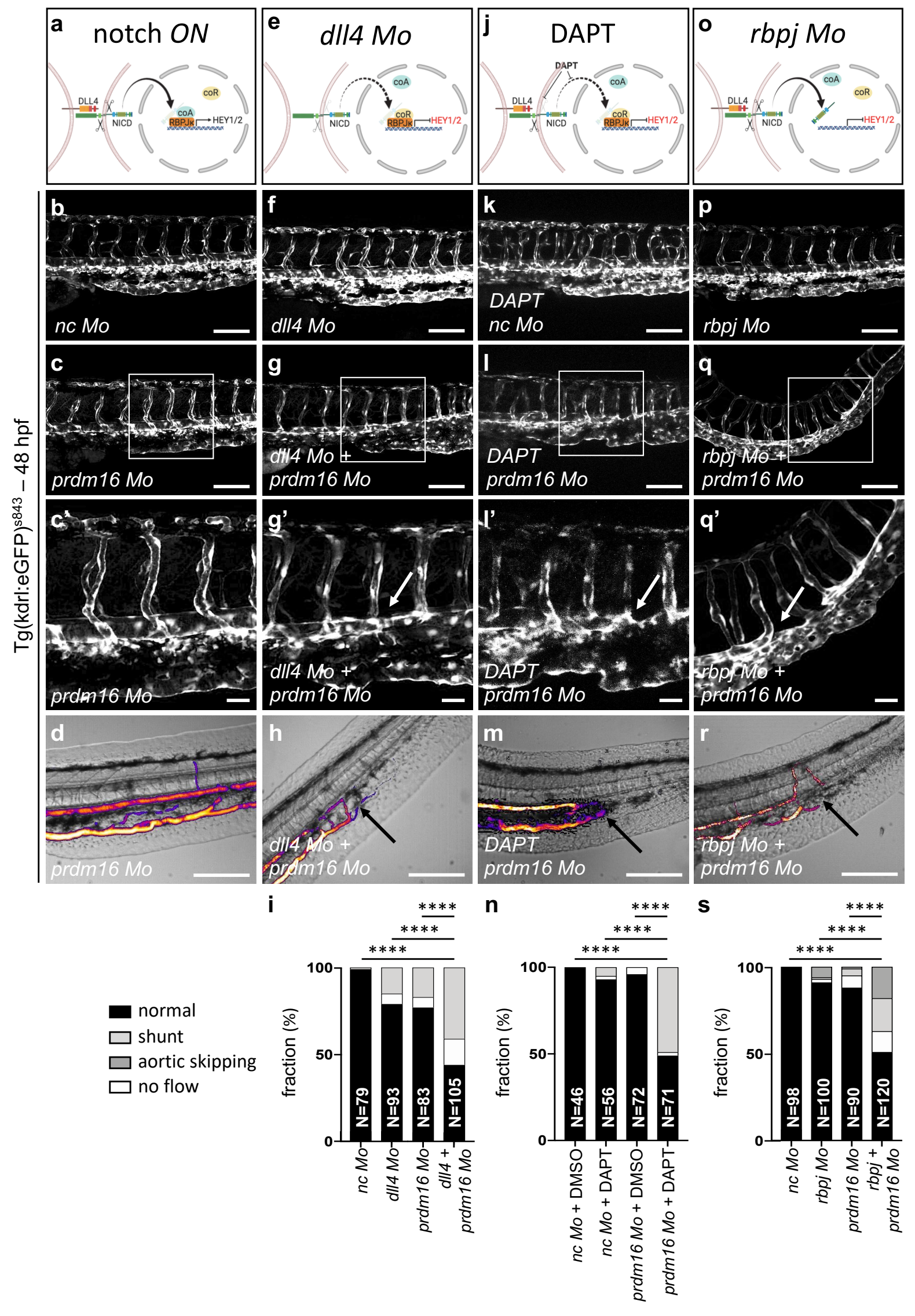


Figure 5. Genetic interaction between prdm16 and the notch signaling pathway during zebrafish vascular development. (a) Schematic overview of normal canonical NOTCH signaling. (b-c') Confocal images of $48 \mathrm{hpf} \operatorname{Tg}(\mathrm{kdrl}: e G F P)^{s 843}$ embryos injected with subthreshold dose of negative control $(n c ; b)$ or $\operatorname{prdm} 16 \mathrm{Mo}\left(c, c^{\prime}\right)$ when notch is ON. (d) Angiogram of a 48 hpf $\operatorname{Tg}(k d r l: e G F P)^{s 843}$ embryo injected with a suboptimal prdm16 Mo dose. (e) Schematic overview of canonical NOTCH signaling in the absence of the notch ligand DLL4. (f-g') Confocal images of $48 \mathrm{hpf} \operatorname{Tg}(\mathrm{kdrl}: e G F P)^{s 843}$ embryos injected with a subthreshold dose of $d l l 4$ Mo alone $(f)$ or both dll4 and prdm16 Mo's $(g, g$ '), demonstrating aortic coarctation defects in compound dll4/prdm16 (white arrow in $g^{\prime}$ ), but not single dll4 or prdm16 morphants. (h) Angiogram of dll4/prdm16 double morphants indicating AV shunting (black arrow). (i) Quantification of the vascular defects in dll4/prdm16 and control embryos. (j) Schematic overview of canonical Notch signaling in the presence of DAPT. (k-l') Confocal images of $48 \mathrm{hpf} \operatorname{Tg}(k d r l: e G F P)^{s 843} n c(k)$ or prdm16 morphant $\left(l, l^{\prime}\right)$ embryos treated with DAPT, indicating aortic coarctation defects (white arrow in $l^{\prime}$ ) in prdm 16 Mo-injected embryos in the presence of DAPT. (m) Angiogram of DAPTtreated prdm16 morphants highlighting AV shunting (black arrow). (n) Quantification of the vascular defects in DAPT or DMSO-treated prdm16 morphant or control embryos. (o) Schematic overview of canonical Notch signaling in the absence of RBPJ $\kappa$. (p-q') Confocal images of $\operatorname{Tg}(k d r l: e G F P)^{s 843}$ embryos injected with suboptimal dose of $r b p j$ Mo $(p)$ or subthreshold doses of both $\operatorname{rbpj}$ and $\operatorname{prdm} 16 \mathrm{Mo}\left(q, q^{\prime}\right)$, the latter resulting in 'aortic skipping' and aortic coarctation (white arrow in $q^{\prime}$ ). (r) Angiogram of $\mathrm{rbpj} / \mathrm{prdm} 16$ double morphants illustrating the presence of an AV shunt (black arrow). (s) Quantification of the vascular defects in rbpj/prdm16 double morphant $v s$. control embryos. Panels labeled with' represent insets. $* * * * P<0.0001$ by Chi square test. Scale bars: $100 \mu \mathrm{m}$ in $b-d, f-h, k-m, p-r ; 25 \mu \mathrm{m}$ in $c^{\prime}, g^{\prime}, l^{\prime}, q^{\prime}$. 


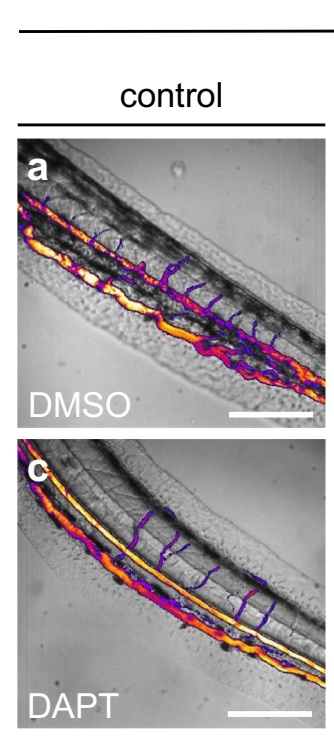

f

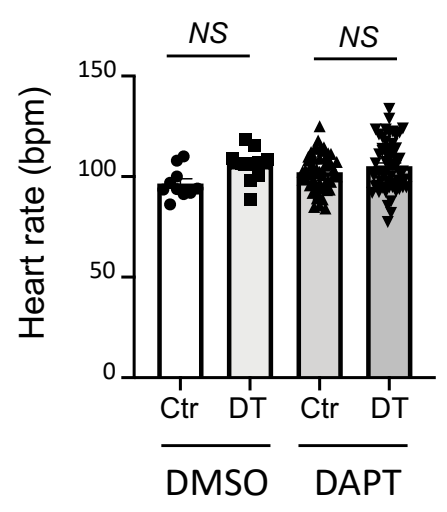

$48 \mathrm{hpf}$

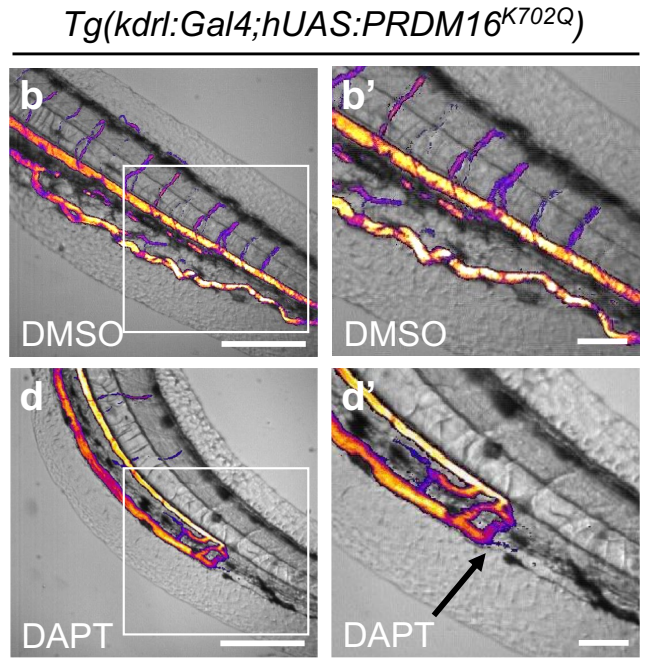

g

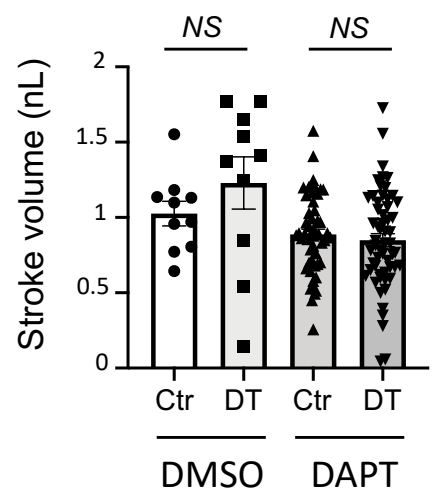

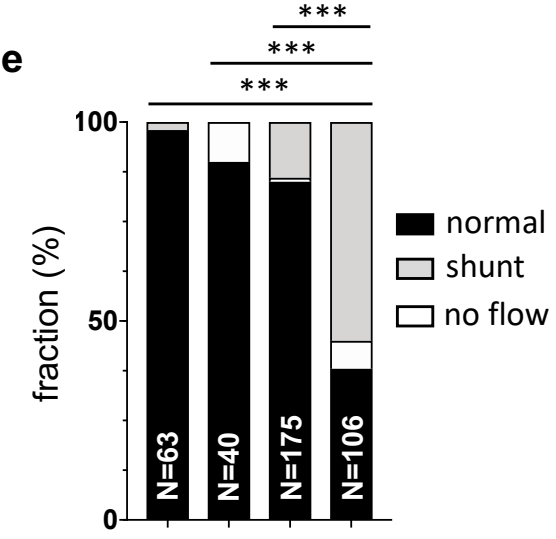

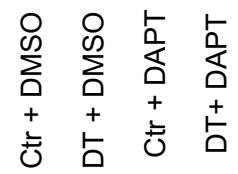

h

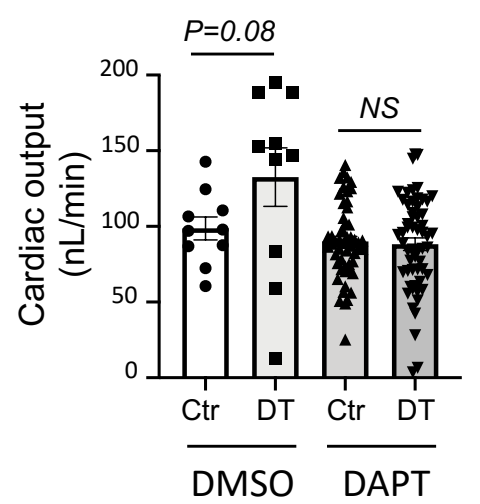

Figure 6. EC-specific overexpression of the dominant-negative PRDM16 ${ }^{\mathrm{K} 702 \mathrm{Q}}$ variant $^{\mathrm{P} e s u l t s}$ in AV shunting in the presence of DAPT. (a-e) Angiograms of $48 \mathrm{hpf}$ control $(a, c)$ and doubletransgenic (DT) $\operatorname{Tg}\left(k d r l: G a l 4 ; U A S: P R D M 16^{K 702 Q}\right)\left(b, b^{\prime}, d, d^{\prime}\right)$ zebrafish larvae treated with DMSO $\left(a-b^{\prime}\right)$ or DAPT $\left(c-d^{\prime}\right)$, indicating shunt formation in DAPT-treated Tg(kdrl:Gal4;UAS:PRDM16 ${ }^{K 702 Q}$ ) embryos (black arrow in d'). (e) Quantification of cardiovascular phenotypes in DMSO and DAPT-treated control and 
$T g\left(k d r l: G a l 4 ; U A S: P R D M 16^{K 702 Q}\right)$ embryos. (f-h) Quantification of heart rate (f), stroke volume $(g)$ and cardiac output $(h)$ of control and DT embryos treated with DMSO or DAPT. ${ }^{* *} P<0.001$; NS: not significant by Chi square (e) or 2-way ANOVA $(f-h)$. Panels labeled with' represent insets. Scale bars: $100 \mu \mathrm{m}$. 


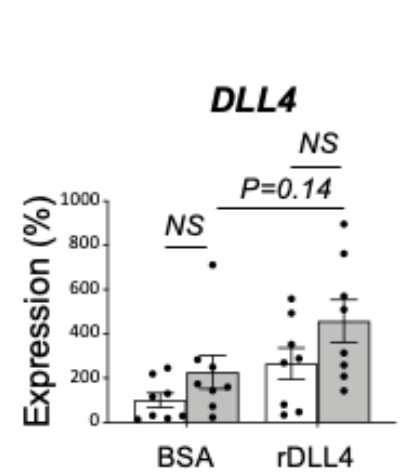

Cherry $\square$ mPrdm16
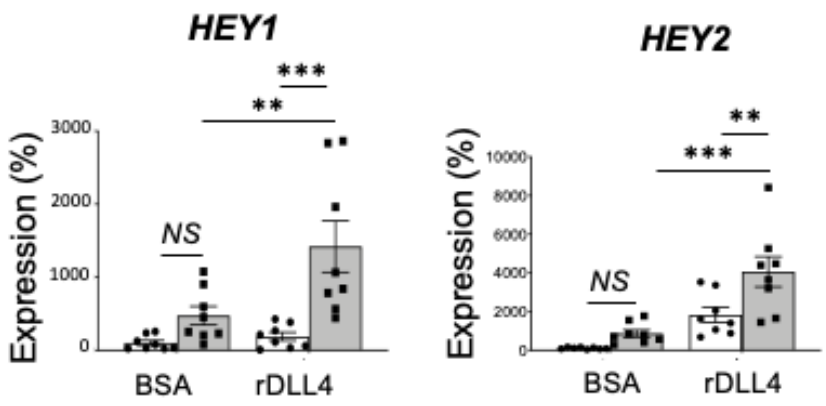

b

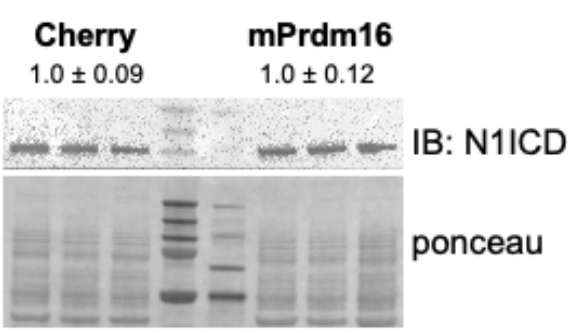

c

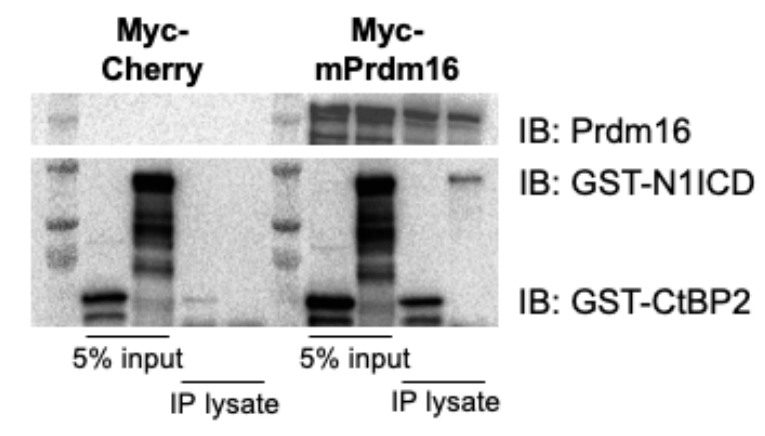

d

$$
\begin{array}{lll}
\frac{5 \% \text { input }}{\mathrm{C} \quad \mathrm{P}} \frac{\mathrm{IP} \text { lysate }}{\mathrm{C} \quad \mathrm{P}} & \begin{array}{l}
\text { IB: MYC } \\
\text { (mPrdm16) }
\end{array} \\
& =\mathrm{IB}: \text { GST (HEY2) }
\end{array}
$$

f

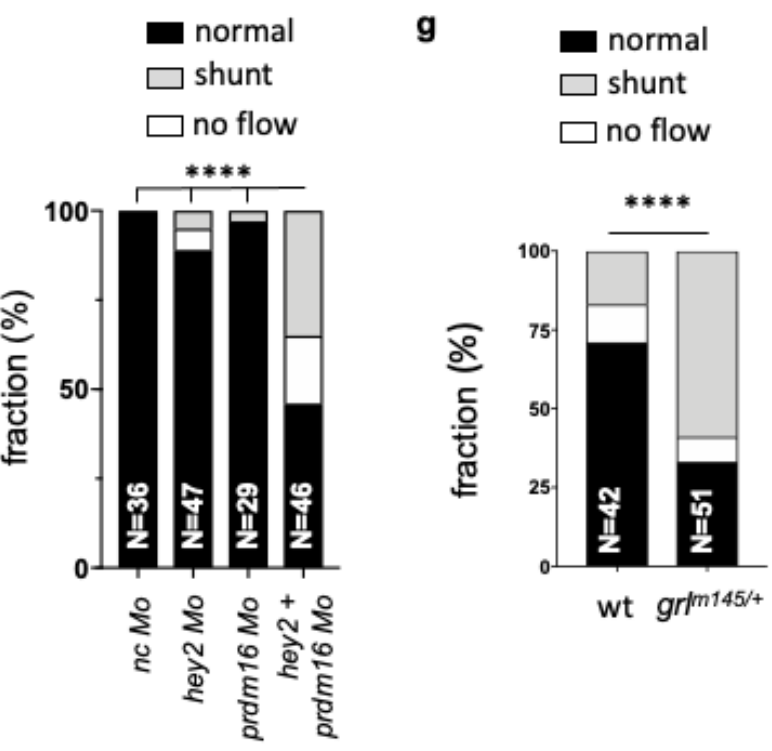

e

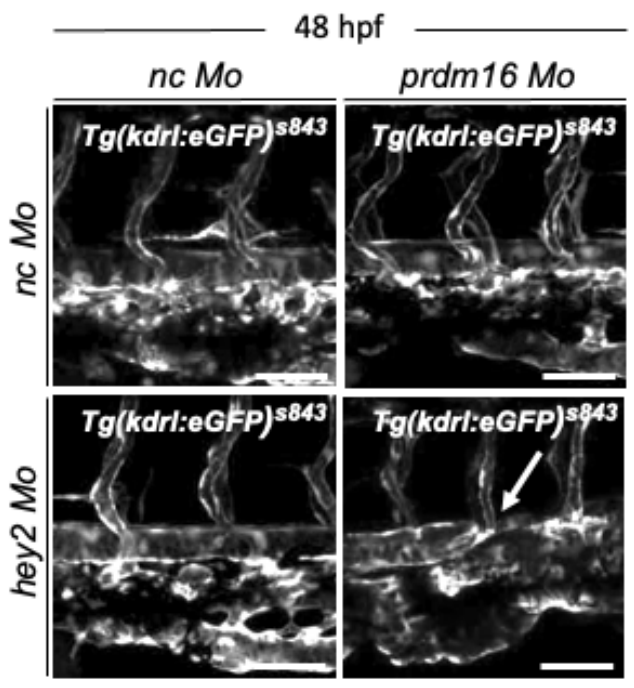

h

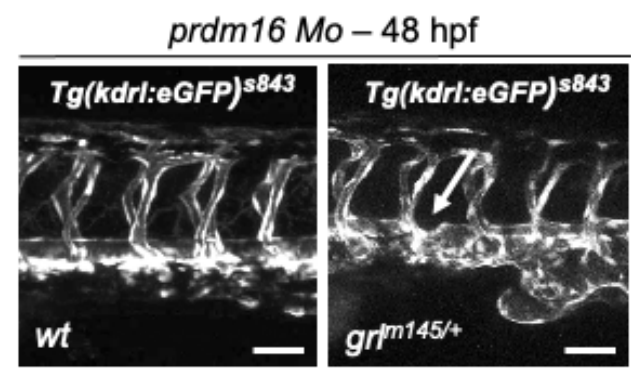


Figure 7. PRDM16 interacts with HEY2 to establish proper arterial development. (a) qRTPCR mRNA analysis for DLL4, HEY1, HEY2 and EFNB2 in Cherry (white bars) or mPrdm16 (gray bars) overexpressing HUVECs grown on BSA or rDLL4-containing gelatin. (b) Western blot for cleaved Notch1ICD (N1ICD) in HUVECs transduced with Cherry or mPrdm16-lentiviral particles. Ponceau red was used to normalize for protein loading. (c,d) Co-immunoprecipitation of Myc-mPrdm16 and GST-N1ICD (c) or GST-HEY2 (d) in Cherry ('C')) or mPrdm16overexpressing ('P') HEK293 cells indicating that PRDM16 and N1ICD or PRDM16 and HEY2 reside in the same protein complex. GST-CtBP2 was used as a positive control (c). (e) Confocal imaging of control (nc), prdm16 or hey2 single morphant and hey2/prdm16 double morphant zebrafish embryos at 48 hpf, indicating aortic coarctation (white arrow) in hey2/prdm 16 double morphants. (f) Quantification of the vascular defects in hey2/prdm16 double morphant vs. control embryos. (g) Quantification of AV shunting in $w t$ and $g r l^{m 145 /+}$ embryos. (h) Confocal imaging of wild-type (wt) and $g r l^{m 145 /+}$ heterozygous embryos on the $T g(k d r l: e G F P)^{s 843}$ background injected with a suboptimal dose of prdm16 Mo. Incomplete knockdown of prdm16 resulted in aortic coarctation (white arrow) in $g r l^{m 145 /+}$, but not $w t$ embryos. $* * P<0.01 ; * * * P<0.001 ; * * * * P<0.0001$; NS: not significant by 2-way ANOVA ( $a$ ) or Chi square test $(f, g)$. Scale bars: $50 \mu \mathrm{m}$ in $e, h$. 